INVESTIGACIÓN/RESEARCH

\title{
EL AUGE DE LOS EMPRENDEDORES. ANÁLISIS DE SU PRESENCIA EN PRENSA EN 2011-2013 Y EN REDES SOCIALES.
}

Félix Fernández Trigueros¹. Técnico de comunicación. (España)

felixtrigueros7@gmail.com

Félix Fernández Castaño. Universidad de Jaén. (España)

fcastano@ujaen.es

\section{RESUMEN:}

El objeto de estudio de esta investigación será la repercusión mediática del emprendimiento tanto en medios especializados económicos como en medios generalistas en prensa del año 2011 y 2013 y las consecuentes variaciones en ese periodo, así como la influencia de las redes sociales en el "auge" de los emprendedores.

El emprendimiento, que se entiende en este estudio, como el proceso de creación de empresas hasta su estabilización es el eje de la investigación. Asimismo, se tendrá en cuenta la aportación de las redes sociales, que es clave para las startups (empresas emergentes), como una herramienta útil de comunicación y marketing y la influencia de éstas para la consecución de los objetivos de los nuevos emprendedores. La ilimitada información que admite Internet, ha permitido que este tema candente haya obtenido más trascendencia en la red que en los soportes tradicionales; siendo éste otro de los objetivos de investigación de este estudio. La mediatización del emprendimiento, a simple vista, debido a la actual crisis económica, se ha visto incrementada por la aprobación de la Ley 11/2013 de 26 de julio de "Medidas de apoyo al emprendedor y de estímulo de crecimiento y de la creación de empleo" y el debate político y social que se ha creado en torno a esta norma.

PALABRAS CLAVE: Emprendimiento-redes sociales-prensa-mediatización

\footnotetext{
${ }^{1}$ Félix Fernández Trigueros: Máster en Periodismo Multimedia Profesional por la Universidad Complutense de Madrid. Periodista en Ideal Granada.
} 


\title{
THE RISE OF ENTREPRENEURS. ANALYSIS OF THEIR PRESENCE IN PRESS EN 2011-2013 AND IN SOCIAL NETWORKS.
}

\begin{abstract}
The purpose of this research study is the media coverage of entrepreneurship both in specialized economic media in general such as media releases of 2011 and 2013 and the consequent variations in that period, as well as the influence of social networks in the "boom " of entrepreneurs.

The venture, which is understood in this study as the process of business creation until stabilization, is the aim of the investigation. It will take into account the contribution of social networks also, which is key for startups (newborn business), as a useful tool for communication and marketing and their influence in achieving the objectives of the new entrepreneurs. The unlimited information that supports Internet, has allowed this hot topic to gain more importance in the network than in traditional media; which is one of the research objectives of this study. Media coverage of the enterprise, at first glance, due to the current economic crisis, has been increased due to the adoption of Law 11/2013 of 26 July " Supporting measures for entrepreneurship and stimulating both growth and creating employment " and the political and social debate that has been created around this rule.
\end{abstract}

KEY WORDS: enterprise - social networks - press -mediation.

\section{INTRODUCCIÓN}

Mediante esta investigación se pretende demostrar un aumento de información sobre emprendimiento en los medios de comunicación y la necesidad por parte tanto de las instituciones políticas como comunicativas de llevar el emprendimiento a cuestión de interés general en España y por tanto, servir de estimulo esta actividad.

En la mayoría de países hoy se tiende a incentivar a los más pequeños en lo que se ha llamado el "espíritu empresarial", motivando y extendiendo las habilidades y competencias requeridas para emprender. También, en casi todas las naciones existen instituciones, proyectos, concursos y congresos cuyo objetivo es precisamente capacitar y construir emprendedores (Schnarch, 2010: 6).

De este estímulo hacia la actividad emprendedora, parecen haberse hecho también responsable los medios de comunicación. El estudio GEM-Spain 2012 (CISE y Fundación Xavier de Salas, 2012: web) presenta un gráfico sobre la percepción de la sociedad de que la información sobre casos de éxito de emprendedores se encuentra cada vez más en los medios de comunicación; tanto entre la población implicada, es decir emprendedores, no implicada y el total.

Gráfico $n^{0}$ (1). Percepción de la población. 


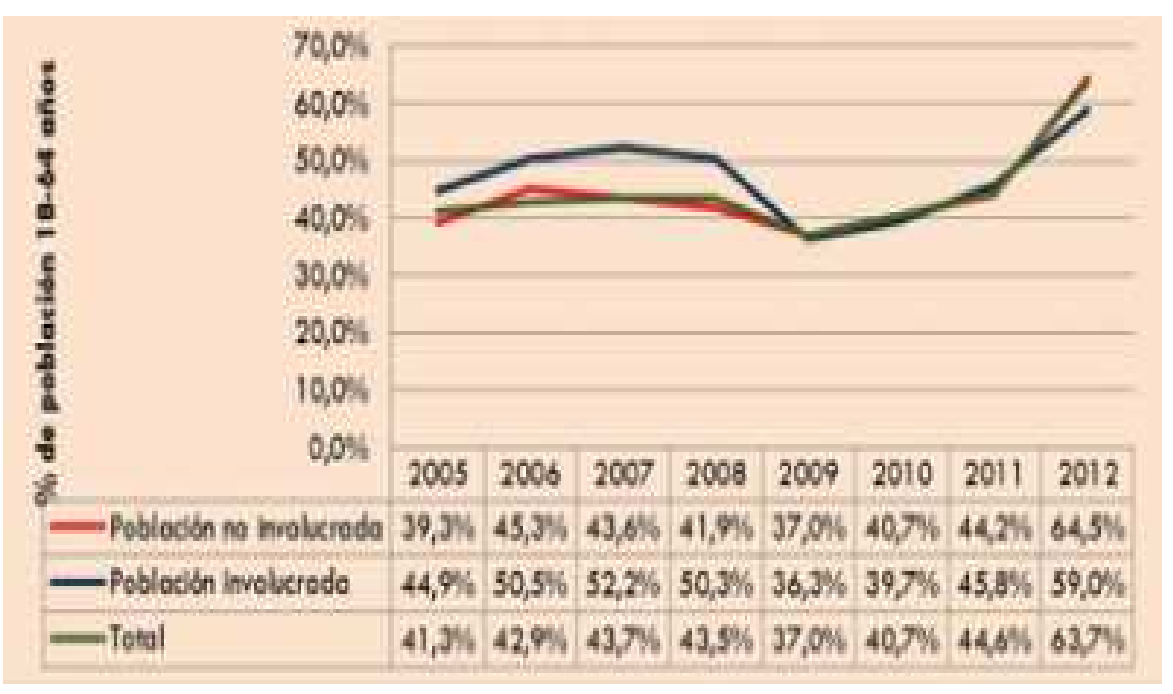

Fuente: GEM-Spain 2012.

En dicho cuadro, de una muestra de 21.900 personas, se percibe que el ciudadano está viendo cómo la contribución de los medios hacia casos de éxito de emprendimiento va aumentado considerablemente, destacándose un incremento significativo entre 2011 y 2012.

Es cierto igualmente, como refleja la estadística presentada, que el ciudadano ha percibido desde hace tiempo la "necesidad" o la "oportunidad" de relatar casos de éxito en los medios por parte de sus editores, redactores... Lo diferenciador, como se ha resaltado, es el aumento de esa consideración en los últimos años, tanto en actores implicados como en no implicados.

Esta representación gráfica de la percepción de la sociedad sobre el emprendimiento se ha visto apoyada por la creación de nuevas secciones dentro de los diarios especializados sobre emprendimiento. Encontramos que el diario Expansión (E\&E, 2012: Web), objeto de análisis en este estudio, inauguró la sección “Emprendedores y Empleo" el 4 de Febrero de 2012 tanto en versión impresa como online. Igualmente:

- El diario El Confidencial (2013: web) lanzaba el 12 de Octubre de 2012 la sección Teknautas que engloba información sobre tecnología y emprendimiento.

- En 2013 nace la web de la agencia de noticias EFE, www.efeempresas.com, dónde incluye una sección titulada "Emprendedores".

Por su parte, la televisión pública española, que puede ser el termómetro de lo que las instituciones políticas quieren construir en el debate público, pondrá en marcha hasta tres programas sobre emprendimiento, sumándose al que ya disponen en el canal 24 horas.

- A partir del próximo mes de Septiembre de 2013, Televisión Española (TVE) ofrecerá un programa televisivo dedicado al emprendimiento presentado por Juan Ramón Lucas llamado “Código Emprende" (EFE, 2013b: Web), en forma de docureality.

- “TVE prepara «Sincronizados», una mirada a los emprendedores en el extranjero" titular del diario ABC (Hoycinema.com, 2013: Web). 
-“Otro espacio sobre emprendedores para intentar salvar la tarde de La 1. La cadena pública estrenará 'Entre todos', un programa sobre la solidaridad, el próximo lunes" recogido el titular del diario El País (Linera, R., 2013: Web).

La investigación sobre emprendedores es un tema actual y pionero, pues no se encuentran estudios sobre información de emprendimiento en los medios y su cuantificación. Según el estudio GEM citado anteriormente, parece que los casos de éxito están a la orden del día o eso, por lo menos, percibe la sociedad; aunque este estudio pretende demostrar que en los últimos años se está publicando información más allá de simplemente casos de éxito.

Del Río (2004: 125), señala que la información relacionada con las empresas obtendrá más importancia y relevancia cuándo afecte a un número representativo de la sociedad.

Dicha visión anterior, es una de las posibles causas por las que el emprendimiento parece estar cada vez más instalado en los medios.

Por su parte, Carlos Otto (E1), vislumbra que los medios cada vez inciden en cubrir más información sobre emprendedores aunque se muestra crítico con la visión de que los medios cuenten casos de éxito en exceso y analiza que:

En los generales cada vez más (hay información sobre emprendedores), aunque aún están anclados en contar solo las historias de éxito: están fascinados con el chavalito que, con 17 años, programa una aplicación y se la vende a Google por 17 millones de euros apenas unos meses después. Saben de sobra que ese no es un periodismo responsable, pero las visitas mandan. Y ese tipo de artículos arrasan.

En cuanto a los económicos, siempre han hablado sobre emprendimiento, aunque ahora ven que, los contenidos que antes nadie visitaba, ahora los lee todo el mundo. Por suerte, los económicos son más rigurosos y tienen un planteamiento más serio.

La ley de Emprendedores (Ley 11/2013 de 26 de julio), contribuye, o es lo que debería pretender, a que España sea uno de los países que se suman a la iniciativa de estimular al emprendimiento entre la sociedad partiendo desde la población más joven. Galindo (2008: 83) señala que "el emprendedor es un factor importante para impulsar el crecimiento de una economía, por lo que deberían ponerse en práctica medidas que fomenten su actividad". Galindo, profesor de la Universidad de Castilla de La Mancha, ya proclamaba la importancia de este estímulo antes de entrar en los momentos más críticos de la crisis coyuntural española. El emprendimiento es importante como generador de empleo y como estímulo de una economía, pero para valorar la inclusión del emprendimiento dentro de los objetivos de una economía de crecimiento hay que tener en cuenta tres consideraciones, que Galindo y Méndez (2008: 33) exponen:

- No queda muy claro el concepto de entrepeneurship o emprendedor, ni siquiera todo lo que habría que incluir en él.

- Habría que plantearse económicamente si no se incluye ya en otro factor económico de la política económica. 
- Aún no existen estadísticas amplías y homogéneas científicas cómo para realizar un estudio empírico.

Habiendo repasado la importancia que tienen los emprendedores para la economía de un país; la investigación estudia la cantidad de información sobre emprendimiento en los medios como baluarte de interés por parte de las fuerzas políticas e institucionales porque el tema entre en el debate público. Para ello, expondremos la función de los emprendedores en la sociedad.

\section{OBJETIVOS}

\section{Objetivo principal:}

- Conocer la repercusión que están teniendo los medios de comunicación y las redes sociales en la mediatización del emprendimiento y todo lo relacionado con éste. Se trata de un estudio aproximativo susceptible de una investigación más amplia.

\section{Objetivos:}

- Descubrir cuál es la realidad del emprendimiento en los medios, completada con la visión de expertos.

- Comparar el número de publicaciones y sus características entre dos diarios de prensa sobre toda la información relacionada con el objeto de estudio.

- Conocer el estado de opinión de los implicados sobre la influencia de las redes sociales y de los medios.

- Verificar si la ley de emprendedores aprobada por el Parlamento español ha influido en una mayor cobertura del emprendimiento en particular y consecuentemente en general.

- Comprobar lo novedoso del emprendimiento, constatando el escaso número de periodistas especializados.

- Obtener una percepción general sobre la mediatización del emprendimiento.

- Profundizar en el conocimiento y en la terminología del emprendimiento.

- Conocer la opinión de expertos, tanto desde el mundo profesional del periodismo como el de la empresa, sobre su percepción del objeto de estudio.

\section{HIPÓTESIS}

Hipótesis principal:

- El auge de los emprendedores se ha visto positivamente reforzado tanto por los medios de comunicación como por las redes sociales.

Hipótesis secundarias:

- La prensa especializada atendió el fenómeno antes que la generalista, pero ambas han dedicado una cobertura cada vez mayor a nuestro tema de investigación.

- Internet se ha postulado como el principal impulsor mediático del emprendimiento.

- La ley de emprendedores aprobada recientemente ha supuesto una mayor atención por parte de los medios hacia el tema. 


\section{METODOLOGÍA}

Se opta por un estudio piloto, para aproximarnos a la realidad del objeto de estudio desde un enfoque metodológico que integra análisis cuantitativos y cualitativos. De una parte se trata de un estudio exploratorio descriptivo no experimental, que emplea la investigación por encuesta (survey study) e inferencial y correlacional (McMillan y Schumacher, 2010). Además de complementarse con otras metodologías de carácter cualitativo, como el análisis de contenido para el análisis de medios (Krippendorf, 1997; López, 2002) y entrevistas a expertos del tema para ahondar en la comprensión de los resultados y tener claves pertinentes para la construcción de los instrumentos de recogida de información y la interpretación de los resultados.

En cuanto al diseño se ha optado por un enfoque secuencial, en el que una información nos iba llevando a otros tipos de análisis y aproximaciones que triangulaban y complementaban la información (Rodríguez, Pozo y Gutiérrez, 2006), aportando consistencia al estudio, pese a su carácter de aproximación (estudio piloto).

Se ha utilizado el programa estadístico SPSS 19, para analizar los diferentes tipos de análisis: descriptivos básicos, frecuencia, contingencias...

Por otro lado, se ha entrevistado a dos expertos del sector (un periodista especializado en el asunto y una autora de dos libros desde una visión más empresarial sobre emprendimiento). Se ha realizado, asimismo, un análisis cuantitativo y relacional de la terminología empleada por éstos.

Para ello, se ha utilizado el software NVIVO que permite la clasificación terminológica en relación a la cuantificación, la longitud y porcentaje ponderado y permite observar y correlacionar términos con expresiones.

El siguiente gráfico crea una relación entre las hipótesis, los objetivos y los análisis realizados para llegar a la consecución de éstos. 


\section{Gráfico $n^{0}$ (2). Relación entre hipótesis, objetivos y métodos de análisis.}

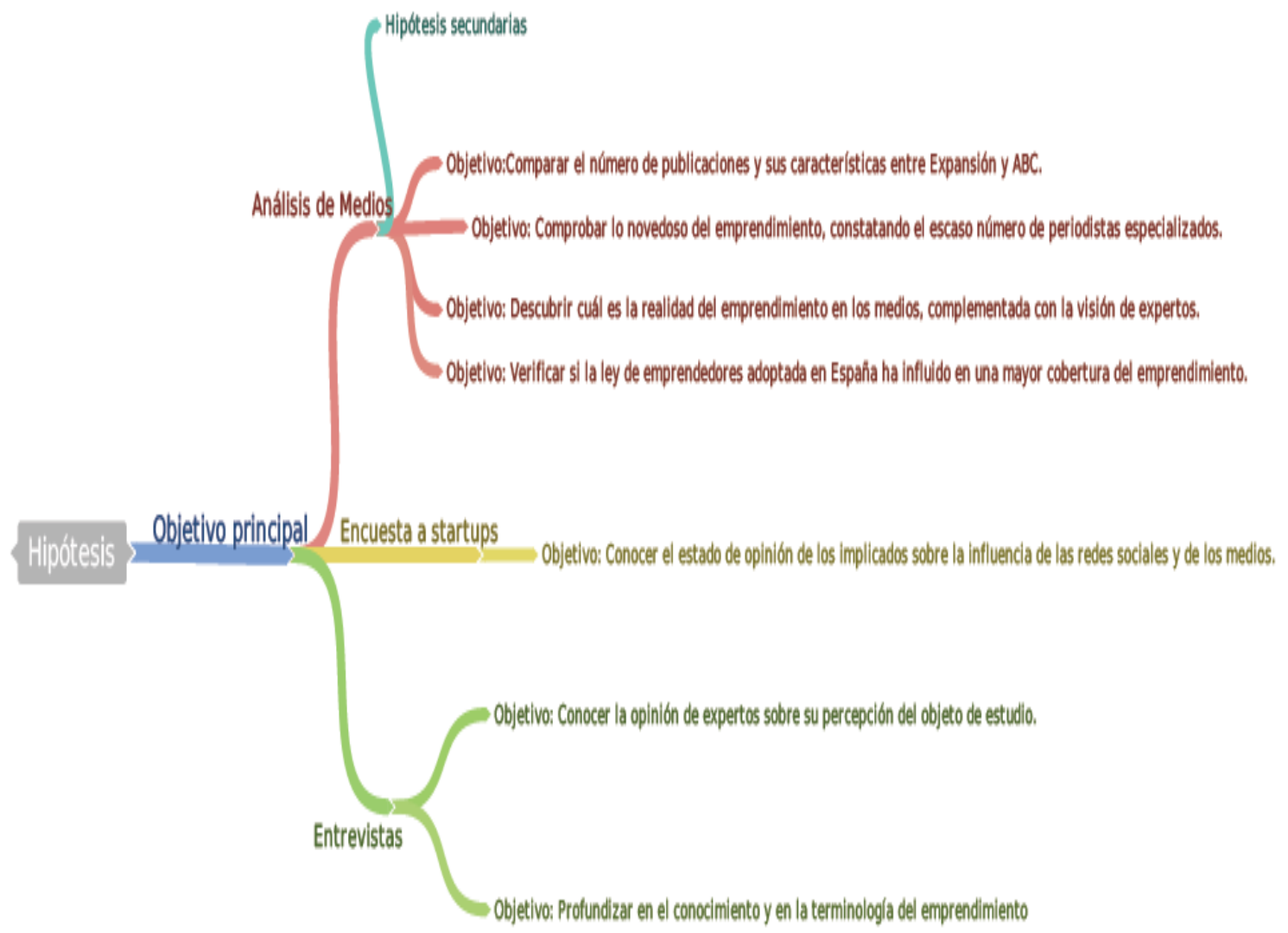

Fuente: elaboración propia.

\subsection{Población y muestra}

Puesto que la población excede las posibilidades del estudio y no se pretende una representatividad de la muestra, sino una aproximación fundamentada (con criterio, no aleatorio) a la realidad, se ha recurrido a los siguientes informantes y fuentes de información.

a) Muestra de las entrevistas.

Para lograr una aproximación al objeto de estudio con mayor criterio y que pueda aterrizar y complementar las referencias teóricas del estudio se han realizado dos entrevistas semiestructuradas a dos personas "expertas" relacionadas con el objeto de estudio:

- Carlos Otto Reus, exredactor en la sección “Tecnología y Emprendedores" del diario El Confidencial. Este periodista aporta una visión intrínseca del tema en los medios de comunicación. Conocedor de la materia al dedicarse profesionalmente a éste y autor de un documental sobre el mismo tema le posiciona como un argumento válido para el estudio. Director del documental "Emprendedores: mentes distintas para tiempos diferentes".

- María Jesús Santiago Segura, licenciada en Sociología y cursando Licenciatura 
Ciencias del Trabajo. Autora de libros sobre emprendimiento, porque aporta la visión desde el ámbito opuesto, es decir desde un lado más empresarial. Conocedora de la materia apoya al objeto de estudio ofreciendo conocimientos desde un punto de vista más teórico. Entre sus trabajos destacan los libros:

- Emprendimiento. Ediciones Albay. 2013. ISBN. ISBN:978-84-937637-8-7

-Innovación Empresarial. Ediciones Albay. 2013. ISBN:978-84-937637-94

b) Muestra de la encuesta

La encuesta realizada sobre 50 startups españolas seleccionadas a través de diferentes plataformas para no condicionar sus respuestas:

- Empresas pertenecientes a la aceleradora de Telefónica, Wayra.

- Empresas que aparecen en el siguiente artículo del diario El Confidencial (2012:

Web): "Las 41 startups españolas con mayor potencial de crecimiento"

- Empresas que aparecen en el buscador de la página: http://www.efeempresas.com

c) Muestra del análisis de medios

El segundo análisis cuantitativo se centra en dos diarios, tanto online como en papel. Los periódicos seleccionados son $\mathrm{ABC}$ y Expansión. La elección de ambos diarios se debe a los valores indicados en el motor de la palabra "emprendedores" que aparecen en la justificación, siendo significativos el número de "palabra encontrada" que aparece en dicho buscador, y cómo ha ido aumentando a lo largo del tiempo. Se ha seleccionado un diario generalista y uno especializado para hacer una comparativa de ambos y vislumbrar si el emprendimiento ha tenido mayor repercusión en uno o en otro o en ambos por igual.

\subsection{Instrumentos de recogida y análisis de información. Parte cuantitativa}

Para poner en marcha el objeto de estudio, se han realizado dos tipos de análisis cuantitativos:

\subsubsection{Cuestionario.}

4.2.1.1 Construcción del Instrumento de recogida de información: Cuestionario.

Se utiliza como instrumento de recogida de información, para obtener una panorámica tanto de los medios de comunicación como de las redes sociales, un cuestionario "online". Pese a haber rastreado la información, no existen instrumentos validados que sirvan al propósito de la investigación. Por ello se optó por construir y validar uno propio: Los emprendedores en los medios de comunicación (ver anexo 1). 
Tabla $n^{0}$ (1). Descripción, objetivo y finalidad de la encuesta.

\begin{tabular}{|c|l|l|l|}
\hline Método & Descripción & Objetivo & \multicolumn{1}{|c|}{ Finalidad para el estudio } \\
\hline \multirow{5}{*}{ Encuesta } & $\begin{array}{l}\text { Encuesta a } \\
50 \text { startups } \\
\text { españolas }\end{array}$ & $\begin{array}{l}\text { Conocer la } \\
\text { opinión de } \\
\text { los } \\
\text { implicados }\end{array}$ & $\begin{array}{l}\text { Aportar una visión complementaria a los } \\
\text { datos extraídos en el análisis de medios. La } \\
\text { opinión de los emprendedores sobre la } \\
\text { influencia que han tenido los medios de } \\
\text { comunicación y las redes sociales en su } \\
\text { visibilidad y notoriedad determinan la causa } \\
\text { por la que está realizada ésta. }\end{array}$ \\
\hline
\end{tabular}

Fuente: elaboración propia.

La encuesta está formada por 11 preguntas con respuesta cerrada única excepto una que es múltiple (ver anexo 1) y pretende obtener una visión de los emprendedores de este país sobre la mediatización del emprendimiento. Las respuestas muestran la visión de las startups en valoraciones ascendentes sobre el pensamiento y sensación de éstas sobre repercusión en su notoriedad y visibilidad debido a los medios de comunicación y las redes sociales, complementando así el análisis de medios. Los ítems están agrupados con cuatro objetivos:

- Conocer cuál es su nombre y su financiación como ítem de organización e interés del estudio y como medio de comparación con otros ítems.

- Conocer la opinión de los actores implicados sobre la percepción de la cantidad de información sobre emprendimiento en los medios de comunicación.

- Conocer la repercusión de las redes sociales en su visibilidad y notoriedad y cuál de ellas ha tenido mayor influencia.

- Conocer en general, de qué manera y sobre qué factores (visibilidad, notoriedad, interés de inversores...) la influencia de los medios y de las redes sociales en las startups.

\subsubsection{Utilización, recogida y análisis de información.}

El sistema de recogida de información ha sido "on line". Para ello se ha utilizado la herramienta ENCUESTATICK.

Se utiliza el programa SPSS 19, para realizar los diferentes tipos de análisis requeridos: fiabilidad, descriptivos básicos, contingencias entre las diferentes dimensiones del estudio.

\subsubsection{Nivel de confianza.}

Si analizamos el tamaño muestral a través de la aplicación online (Sample Size Calculator For A Proportion Absolut Margin) obtenemos los siguientes parámetros del cálculo:

Nivel de confianza $=0.89$

Margen de error $=0.11$

Proporciones $=0.5$

Los resultados lo podemos obtener de la siguiente imagen capturada de la aplicación. 
Tabla $\mathbf{n}^{\circ}$ (2). Nivel de confianza de la encuesta.

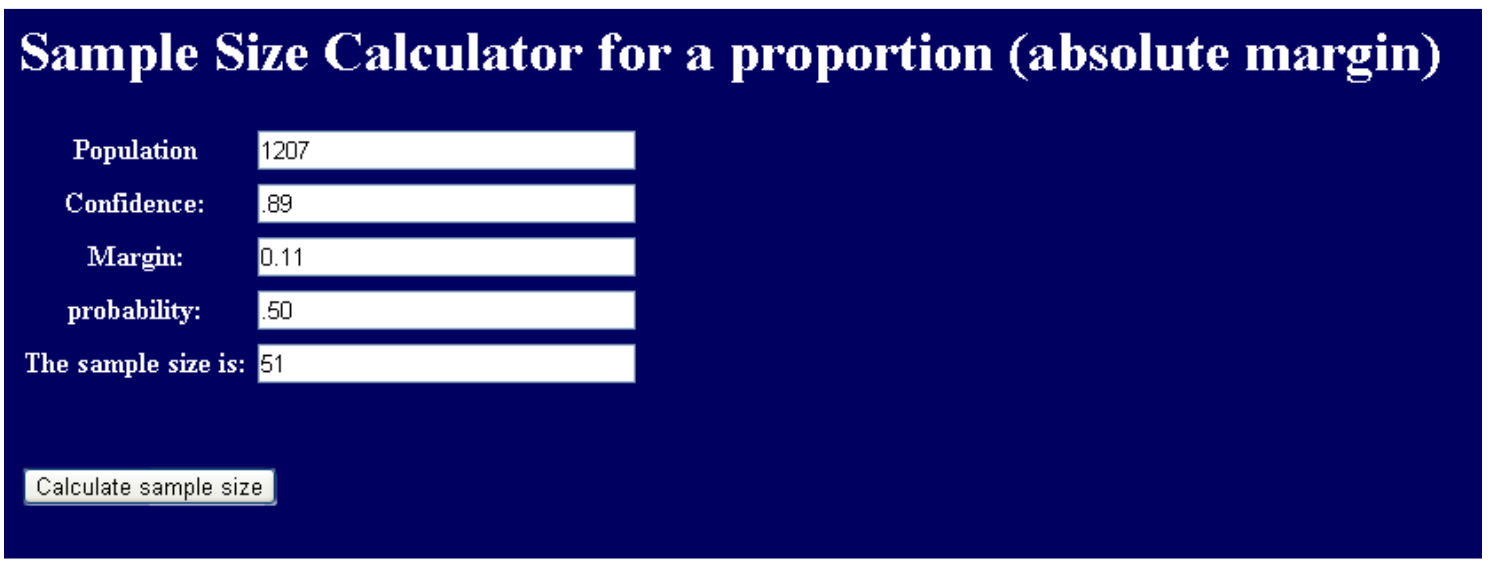

Con cerca de un intervalo de confianza del $90 \%$ y un margen de error del $11 \%$ se presenta el análisis de las 50 empresas, como queda reflejado en la anterior imagen.

\subsubsection{Validez y fiabilidad.}

El cuestionario se elaboró, de manera sintética, tomando en consideración los principales elementos de contenido emergentes de las aproximaciones al tema y toda la revisión teórica sobre el mismo. Para comprobar la validez de contenido del instrumento del estudio se sometió a juicio de expertos, tanto profesorado del máster como profesionales en activo de la Agencia EFE, donde realicé mis prácticas.

El instrumento tiene una adecuada validez de construcción, pues se obtiene unas adecuadas medidas en las pruebas KMO y prueba de Bartlett, además de que se explica el 70,766 \% de la varianza de respuesta en torno a cuatro dimensiones lógicas con el contenido del cuestionario.

Tabla $n^{0}$ (3). Datos de fiabilidad de la encuesta. KMO y prueba de Bartlett

\begin{tabular}{|ll|r|}
\hline $\begin{array}{l}\text { Medida de adecuación muestral de Kaiser- } \\
\text { Meyer-Olkin. }\end{array}$ &, 657 \\
\begin{tabular}{ll|} 
Prueba de esfericidad \\
de Bartlett
\end{tabular} & $\begin{array}{l}\text { Chi-cuadrado } \\
\text { aproximado }\end{array}$ & 121,080 \\
& gl & 36 \\
& Sig. &, 000 \\
\hline
\end{tabular}


Varianza total explicada

\begin{tabular}{|c|c|c|c|c|c|c|c|c|c|}
\hline \multirow[b]{2}{*}{$\begin{array}{l}\text { Comp } \\
\text { o- } \\
\text { nente }\end{array}$} & \multicolumn{3}{|c|}{ Autovalores iniciales } & \multicolumn{3}{|c|}{$\begin{array}{c}\text { Sumas de las saturaciones } \\
\text { al cuadrado de la } \\
\text { extracción }\end{array}$} & \multicolumn{3}{|c|}{$\begin{array}{l}\text { Suma de las saturaciones } \\
\text { al cuadrado de la rotación }\end{array}$} \\
\hline & Total & $\begin{array}{l}\text { \% de la } \\
\text { varian } \\
\text { za }\end{array}$ & $\begin{array}{c}\% \\
\text { acumulad } \\
\mathrm{o}\end{array}$ & Total & $\begin{array}{l}\% \text { de la } \\
\text { varian } \\
\text { za }\end{array}$ & $\begin{array}{c}\% \\
\text { acumulad } \\
\mathrm{o}\end{array}$ & Total & $\begin{array}{c}\% \text { de la } \\
\text { varian } \\
\text { za }\end{array}$ & $\begin{array}{c}\% \\
\text { acumulad } \\
\text { o }\end{array}$ \\
\hline 1 & 2,692 & 29,914 & 29,914 & 2,692 & 29,914 & 29,914 & 2,571 & 28,563 & 28,563 \\
\hline 2 & 1,505 & 16,721 & 46,635 & 1,505 & 16,721 & 46,635 & 1,604 & 17,822 & 46,385 \\
\hline 3 & 1,147 & 12,749 & 59,385 & 1,147 & 12,749 & 59,385 & 1,149 & 12,766 & 59,151 \\
\hline 4 & 1,024 & 11,382 & 70,766 & 1,024 & 11,382 & 70,766 & 1,045 & 11,616 & 70,766 \\
\hline 5 & ,930 & 10,332 & 81,099 & & & & & & \\
\hline 6 & ,780 & 8,668 & 89,766 & & & & & & \\
\hline 7 & ,493 & 5,481 & 95,247 & & & & & & \\
\hline 8 & 288 & 3,203 & 98,450 & & & & & & \\
\hline 9 & 139, & 1,550 & 100,000 & & & & & & \\
\hline
\end{tabular}

Método de extracción: Análisis de Componentes principales.

El análisis factorial del cuestionario nos muestra cómo tiene una suficiente validez de constructo, puesto que el 70,766 \% de la varianza es explicada en torno a cuatro componentes. Éstos podrían denominarse del siguiente modo:

1. Grado de cobertura de los medios de información, tanto de carácter general como especializado, en papel y online.

2. Contribución de los medios y redes sociales a dar visibilidad y notoriedad a la empresa o proyecto.

3. Antigüedad de la empresa y contribución de los medios al interés de los inversores.

4. Medio de difusión sobre emprendedores. 
Tabla $n^{0}$ (4). Análisis factorial: Matriz de componentes rotados.

\begin{tabular}{|l|r|r|r|r|}
\hline & \multicolumn{4}{|c|}{ Componente } \\
\cline { 2 - 5 } & \multicolumn{1}{|c|}{1} & \multicolumn{1}{c|}{2} & \multicolumn{1}{l|}{3} & \multicolumn{1}{c|}{4} \\
\hline TIEMPO EMPRESA &, 029 &, 156 &, 621 &,- 357 \\
I.GENERAL &, 875 &, 090 &, 149 &,- 042 \\
I.ESPECIALIZADA &, 940 &, 069 &,- 088 &, 050 \\
I.ESP.ONLINE &, 925 &, 022 &,- 039 &,- 101 \\
MEDIO &,- 057 &,- 016 &, 019 &, 882 \\
CONTRIBUCION.M.S &,- 058 &, 750 &,- 158 &,- 002 \\
CONTRIBUCION.R.S &, 240 &, 742 &, 216 &, 190 \\
RED.SOCIAL &,- 047 &,- 661 &,- 017 &, 189 \\
CONTRIBUCIÓN.INV &,- 020 &,- 125 &, 812 &, 232 \\
ERSORES & & & & \\
\hline
\end{tabular}

Método de extracción: Análisis de componentes principales.

Método de rotación: Normalización Varimax con Kaiser.

La rotación ha convergido en 4 iteraciones.

Con el objetivo de averiguar el grado de la fiabilidad de este cuestionario fue aplicado el coeficiente (Cronbach Alfa). Obteniendo un alfa aceptable para una muestra piloto.

Tabla $n^{0}$ (5). Datos de fiabilidad de la encuesta: Alfa de Cronbach.

\begin{tabular}{|c|c|c|}
\hline $\begin{array}{l}\text { Alfa de } \\
\text { Cronbach }\end{array}$ & $\begin{array}{l}\text { Alfa de } \\
\text { Cronbach } \\
\text { basada en } \\
\text { los } \\
\text { elementos } \\
\text { tipificados }\end{array}$ & $\mathrm{N}$ de elementos \\
\hline 305, & 427, & 9 \\
\hline
\end{tabular}


Resumen del procesamiento de los casos

\begin{tabular}{|rl|r|r|}
\hline & & \multicolumn{1}{|c|}{ N } \\
\hline Casos & Válidos & 50 & 100,0 \\
& $\begin{array}{l}\text { Excluido } \\
\text { s }\end{array}$ & 0 &, 0 \\
& & \\
Total & 50 & 100,0 \\
\hline
\end{tabular}

Eliminación por lista basada en todas las variables del procedimiento.

\subsection{Instrumentos de recogida y análisis de información. Parte cualitativa.}

La principal clave para asegurar la validez científica en la investigación cualitativa (Flick, 2007) consiste en decidir y delimitar claramente qué se ha de observar y registrar, y lo que se considera como «dato» (Holton, 2007; Corbin \& Strauss, 2008), como para poder hacer visible la toma de decisiones adoptada y se pueda replicar en las mismas circunstancias. Aunque, como defiende López (2002: 175), más que dato, sería más acertado hablar de «datos», ya que toda investigación de carácter empírico abarca una multitud de unidades portadoras de información. En nuestro caso ha sido construida (tanto para analizar la entrevistas como los medios) en torno a categorías que agrupan unidades de sentido (frases y párrafos) bien determinadas; lo que implica delimitar su definición, su separación, teniendo en cuenta sus respectivos límites y su identificación para el análisis (Krippendorf, 1997, p.81).

\subsubsection{Análisis de contenido (medios de comunicación).}

Para observar la repercusión que ha tenido el emprendimiento en los medios de comunicación se procederá a analizar un diario especializado en asuntos económicos, en este caso Expansión y un diario de información generalista, en este caso ABC.

\subsubsection{La técnica empleada.}

Entendemos con Andréu (2003) y Krippendorf (1997) que el análisis de contenido en un sentido amplio, como una técnica de interpretación de textos, siguiendo el método científico, es decir, de manera sistemática, objetiva, replicable, y valida. Y se puede interpretar tanto de una forma directa y manifiesta o de una forma inferida, extrayendo su sentido latente, oculto o lo que dice sin pretenderlo. De todas las modalidades de análisis de contenido, se realiza más propiamente un análisis documental tematizado, para recoger, sistematizar y agrupar la información objeto de estudio. En este caso se ha optado por un doble enfoque del análisis de contenido 
(Gómez, 2000): cuantitativo, en cuanto se contabilizan las frecuencias, y cualitativo, puesto que "se interpreta y valora" en función del contenido y del valor de la información en función de los criterios periodísticos (género, sección, etc.).

4.3.1.2. Procedimiento de recogida y análisis de información.

Seguidamente se presentan los diferentes elementos o pasos seguidos en el proceso de análisis: Determinar el objeto o tema de análisis, así como las reglas de codificación y categorías, asegurar la fiabilidad del sistema y extraer inferencias.

Tabla $n^{\circ}$ (6). Descripción, objetivo y finalidad del análisis de medios.

\begin{tabular}{|c|c|c|c|}
\hline $\begin{array}{l}\text { Método de } \\
\text { análisis }\end{array}$ & Descripción & Objetivo & Finalidad \\
\hline $\begin{array}{l}\text { Análisis de } \\
\text { medios }\end{array}$ & $\begin{array}{l}\text { Análisis de dos } \\
\text { medios nacionales } \\
\text { durante los meses de } \\
\text { marzo, abril y mayo } \\
\text { de } 2011 \text { y 2013: } \\
\text { * ABC (Generalista) } \\
\text { * Expansión } \\
\text { (Especializado en } \\
\text { Economía) }\end{array}$ & $\begin{array}{l}\text { Determinar la } \\
\text { cantidad de } \\
\text { información } \\
\text { publicada sobre } \\
\text { emprendedores y } \\
\text { realizar una } \\
\text { comparativa } \\
\text { entre un medio } \\
\text { generalista y uno } \\
\text { especializado en } \\
\text { economía. }\end{array}$ & $\begin{array}{l}\text { Verificar que hay una } \\
\text { mayor cantidad de noticias } \\
\text { publicadas en } 2013 \text { en } \\
\text { comparación con } 2011 \text { y } \\
\text { que los medios online } \\
\text { también han contribuido a } \\
\text { que exista una mayor } \\
\text { mediatización del asunto. }\end{array}$ \\
\hline
\end{tabular}

Fuente: elaboración propia.

Para el análisis de los diarios (tanto online como en papel) seleccionados, se empleó el siguiente tiempo de análisis: 3 meses, excluyendo sábados y domingos, (marzo, abril y mayo) para el formato impreso y de 10 días seleccionado al azar entre esos 3 meses en formato online. Se ha realizado en 2011 y 2013 en los medios impresos y en 2013 en el online.

La elección de los años 2011 y 2013 se debe sobre todo a que, cómo veremos más adelante en el marco teórico, el paso del 2011 al 2012 fue un año de transición en la percepción por parte de la sociedad sobre la cantidad de información sobre casos de éxito de emprendedores que aparecen en los medios de comunicación.

En formato papel, los datos de 2013 fueron extraídos a través del seguimiento de los ejemplares correspondientes, archivado en la Hemeroteca Nacional situada en Madrid, por lo que sábados y domingos de ambos diarios no aparecen en la búsqueda (adicionándose el 30 de abril, 1 de mayo y 13 de mayo debido a que no se encontraban disponibles). En el caso de los datos de 2011, el seguimiento se realizó a través de los ejemplares consultados en la Biblioteca Regional de Madrid Joaquín Leguina (excluyendo igualmente sábados y domingos).

En formato online, los datos son extraídos, de manera no vinculante completamente, 
señalando la palabra en ambos buscadores "emprendedores" y delimitando el día fechado.

La elección de sólo hacer 10 días en el formato online se debe a que es prácticamente inviable ser más concretos a posteriori, ya que la cantidad que éstos permiten es ilimitada. Se trata simplemente de realizar una comparación orientativa de determinados días. Se trata de una clasificación que no es totalmente vinculante pues puede haber artículos sobre emprendedores que no contengan dicho término.

En este caso han seleccionado 10 días aleatoriamente entre los tres meses (marzo, abril y mayo, más concretamente 8/03/2013, 13/03/2013, 21/03/2013, 04/04/2013, 12/04/2013, 24/04/2013, 03/05/2013, 08/05/2013, 17/05/2013 y 25/05/2013).

En el análisis de noticias diarias de los medios, los ítems analizados son:

\section{Tabla $\mathbf{n}^{0}$ (7). Ítems expuestos en el análisis de medios.}

\begin{tabular}{|c|c|}
\hline $\begin{array}{l}\text { Fecha } \\
\text { (Impreso y online) }\end{array}$ & $\begin{array}{l}\text { Determina la cantidad de información publicada relacionándolo } \\
\text { con el objetivo de la importancia de la ley de emprendedores. }\end{array}$ \\
\hline $\begin{array}{l}\text { Sección } \\
\text { (Impreso y online) }\end{array}$ & $\begin{array}{l}\text { Determina la amplitud o no del emprendimiento en diferentes } \\
\text { secciones, lo que provocaría una mayor o menor relevancia según } \\
\text { frecuencia, diversidad e importancia de situarse en una o en otra. }\end{array}$ \\
\hline $\begin{array}{l}\text { Género } \\
\text { (Impreso y online) }\end{array}$ & $\begin{array}{l}\text { Determina el tipo de información (noticia, entrevista, reportaje...) } \\
\text { y su consecuente mayor o menor repercusión. }\end{array}$ \\
\hline $\begin{array}{l}\text { Columnas } \\
\text { (Impreso) }\end{array}$ & $\begin{array}{l}\text { Determina la cobertura que se hace de dicha información, más } \\
\text { extensa o menos. }\end{array}$ \\
\hline $\begin{array}{l}\text { Firma } \\
\text { (Impreso y online) }\end{array}$ & $\begin{array}{l}\text { Apoyará o no el objetivo de verificar si existen pocos periodistas } \\
\text { especializados en emprendimiento. }\end{array}$ \\
\hline $\begin{array}{l}\text { Tema } \\
\text { (Impreso y online) }\end{array}$ & $\begin{array}{l}\text { Determinará que tipo de informaciones hay (ley de emprendedores, } \\
\text { consejos, historias personales...), lo que influirá en una mayor o } \\
\text { menor relevancia según la frecuencia y la diversidad. }\end{array}$ \\
\hline
\end{tabular}

\section{Fuente elaboración propia.}

Se han seleccionado estos indicadores que determinan la importancia de las noticias analizadas. La relevancia reside en el número de informaciones, en qué secciones se localizan éstas (si sólo en una o se posicionan en diferentes), en qué página aparecen, que temática tienen (si sólo se habla, por ejemplo, de la ley de emprendedores o los 
asuntos son más actuales o de otro tipo de interés), determinando así una mayor repercusión en el medio.

El indicador de la firma persigue un objetivo diferente en el estudio. Pretende demostrar que debido al escaso tiempo que lleva este tipo de informaciones en los medios de manera más regular, el número de profesionales especializados es escaso, por lo que existe una amplia diversidad, lo que demuestra que no hay periodistas específicos para los noticias sobre emprendimiento.

\subsection{Entrevistas.}

Por último, las entrevistas a expertos se han realizado siguiendo un formato semiestructurado, tanto para facilitar tanto la sistematización de la información obtenida y que no queden huecos o puntos en blanco en las mismas, como para facilitar el desarrollo dialógico de las mismas, ofreciendo más libertad y margen a los entrevistados.

La metodología de análisis utilizada combina el análisis de discurso (Fernández, 2005), con los propios del análisis de contenido (Krippendorff, 1990). Se ha utilizado un sistema de categorías y relaciones que permiten la interpretación de los datos (Cohen y Manion, 1994; Strauss y Corbin, 2002; Corbin \& Strauss, 2008; Flick, 2007). Este sistema partió, en un primer momento de la teoría (categorías predeterminadas), pero, seguidamente, se fue completando, enriqueciendo y contrastado a partir de las propias evidencias y giro del propio debate con los informantes clave.

Como herramienta de análisis de datos se utilizó el software Nvivo 10 tanto para análisis de categorías, frecuencia de palabras y mapa de árbol. Siempre se utiliza un análisis global y seguidamente se hacen relaciones más frecuentes y árboles de palabras -a modo de tres niveles de profundidad- para encontrar los matices que se escapan del uso de conceptos determinados. Con lo que se conseguía, además de profundidad, validez mediante la triangulación (Rodríguez, Pozo y Gutiérrez, 2006). Las unidades de sentido, categorías o elementos sobre los que realizar el análisis de las entrevistas han sido las siguientes:

\section{Tabla $n^{0}(8)$. Ítems de las entrevistas.}

\begin{tabular}{|l|l|}
\hline Categoría & Descripción y justificación \\
\hline $\begin{array}{l}\text { Medios de } \\
\text { comunicación }\end{array}$ & $\begin{array}{l}\text { Se analizará el término "medios de comunicación" cuestionado } \\
\text { en este caso como posible causante de la mediatización del } \\
\text { emprendimiento y la opinión de los expertos, tanto desde un } \\
\text { punto de vista más implicado (caso del periodista) como otro no } \\
\text { implicado. }\end{array}$ \\
\hline Redes sociales & $\begin{array}{l}\text { Las "redes sociales", e Internet en general, son una herramienta } \\
\text { que permite aportar, obtener y difundir información y conseguir } \\
\text { una repercusión sobre los potenciales clientes que pueda tener } \\
\text { un emprendedor. Para ello, se le cuestiona sobre este } \\
\text { instrumento para conocer la opinión desde su experiencia. }\end{array}$ \\
\hline Emprender & Emprender conlleva una serie de implicaciones y no tiene \\
\hline
\end{tabular}




\begin{tabular}{|l|l|}
\hline & $\begin{array}{l}\text { porque ser necesariamente desde un punto de vista empresarial. } \\
\text { Para ello, se les consulta sobre qué es, cómo funcionan, qué hay } \\
\text { que tener en cuenta y de qué hay que estar alerta. }\end{array}$ \\
\hline Personas & $\begin{array}{l}\text { El concepto de emprendedor se asocia a personas y, no tanto a } \\
\text { negocios, por lo que es interesante conocer las referencias que se } \\
\text { hacen sobre éstas y las cualidades que puedan aportar los } \\
\text { entrevistados. }\end{array}$ \\
\hline
\end{tabular}

Fuente: elaboración propia.

\section{RESULTADOS}

\subsection{Análisis de medios.}

Los resultados obtenidos del análisis de medios se irán desarrollando desde una percepción más general hacia detalles más concretos, respondiendo así poco a poco a los objetivos expuestos anteriormente. Para empezar, vemos el número de noticias totales:

A) Número de noticias totales:

\section{Gráfico $n^{0}$ (3). Noticias totales por medio impreso y año.}

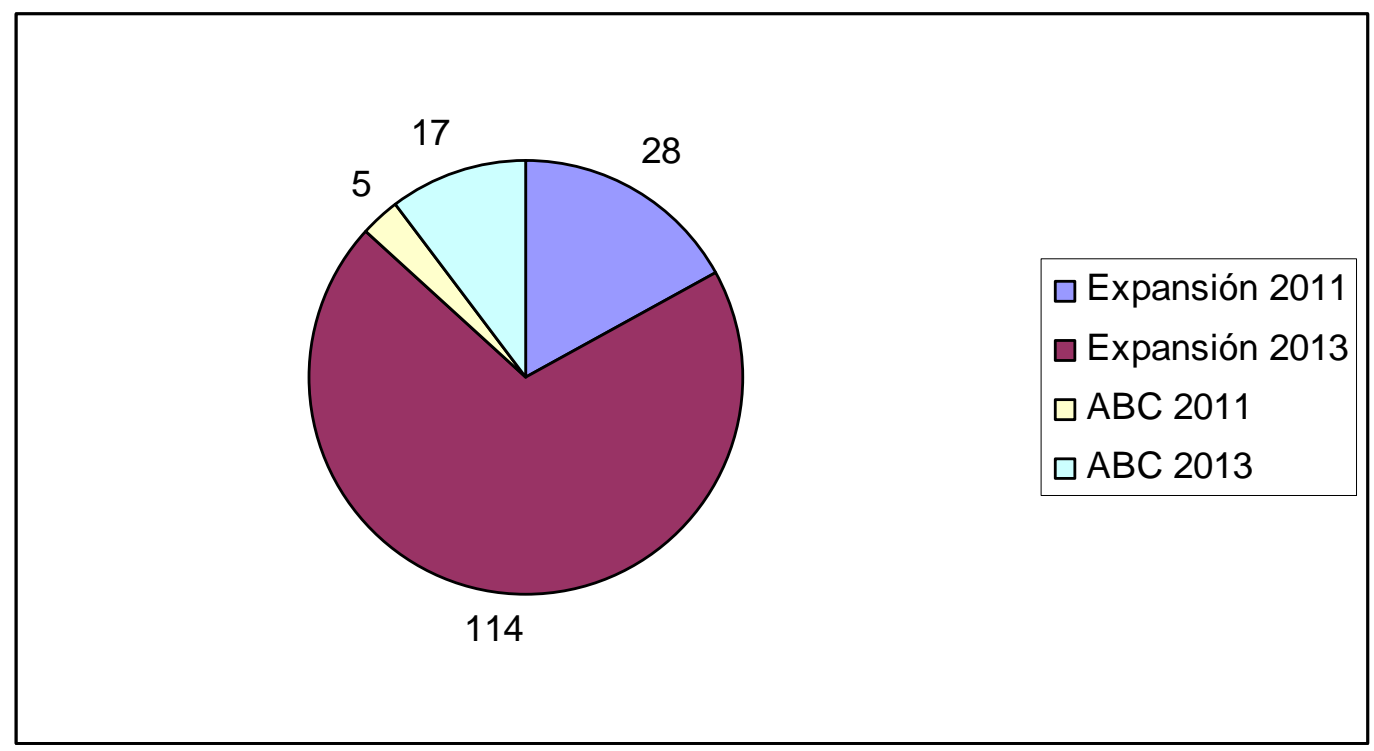

Fuente: elaboración propia.

En el gráfico se puede obtener los datos de que en el año 2013 tanto el diario Expansión como en el diario $\mathrm{ABC}$ tienen mucha más cobertura de informaciones sobre emprendimiento en 2013 que en 2011. Más concretamente, el diario Expansión tiene 114 en 2013 frente a las 28 en 2011. Por otro lado, el ABC tiene 17 en 2013 frente a las 5 en 2011.

Por lo tanto, se puede percibir a simple vista, asimismo, que la cobertura de artículos es muy superior en el caso del diario especializado frente al generalista. Dicho 
análisis, en principio, es lógico teniendo en cuenta que la información sobre emprendimiento es más viable que aparezca en un diario económico.

Carlos Otto (E1), comparte esta visión que advierte que en diarios económicos siempre ha habido información sobre emprendedores aunque ahora está teniendo mucha más audiencia y que

cuando escribes sobre emprendimiento en un medio económico, es muy probable que tu lector sea emprendedor o se lo haya planteado muchas veces. Cuando escribes en un generalista, tu lector puede ser cualquiera. Al lector de un medio económico siempre le van a atraer mucho más los temas de emprendedores que al de un medio generalista.

Si realizamos una comparativa global, obtenemos el siguiente gráfico:

\section{Gráfico $n^{\circ}$ (4). Noticias totales en medio impreso por año.}

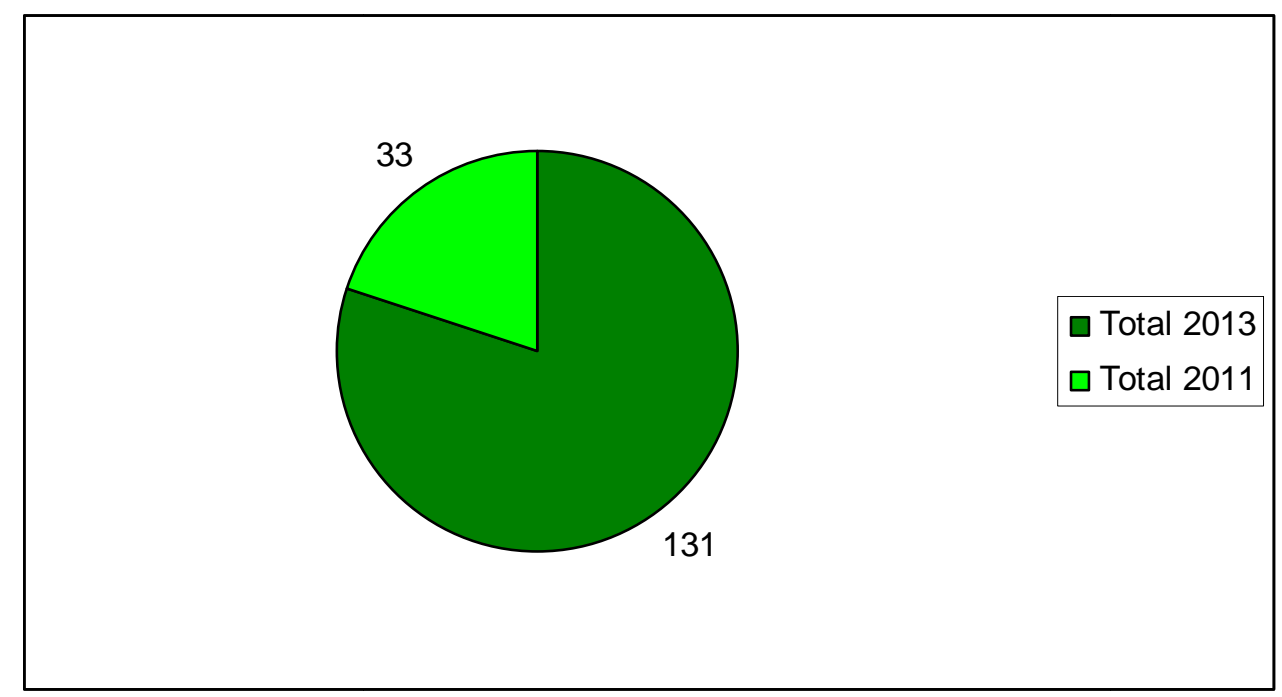

Fuente: elaboración propia.

Se puede apreciar que en 2013 aumentó muy significativamente la información sobre emprendedores respecto a 2011. Más concretamente, ha aumentado en un $645 \%$ la información de 2013 respecto a 2011.

A.1) Número de noticias impresas vs. Online en 2013.

En el caso del diario ABC:

Gráfico no (5). Noticias ABC 2013 por formato.
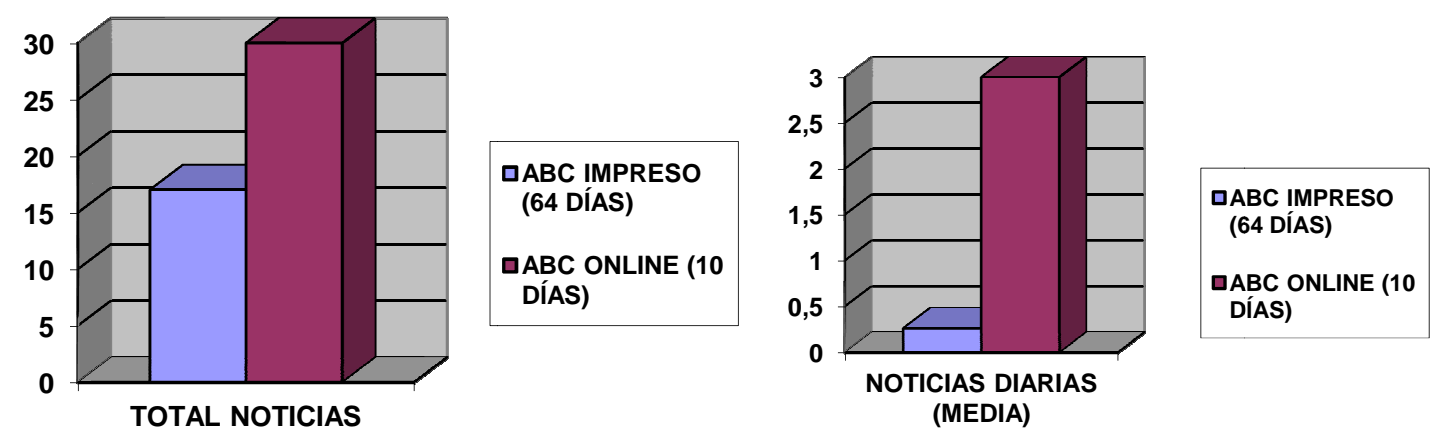

DABC IMPRESO (64 DÍAS)

ABC ONLINE (10 DÍAS)

(MEDIA) 
Fuente: elaboración propia.

Con una búsqueda, simplemente de la palabra "emprendedores", por lo que podría haber más, el número de noticias publicadas aumenta considerablemente respecto al impreso. Más concretamente, en el formato online encontramos hasta 30 informaciones realizando esta búsqueda respecto a las 17 que encontramos a lo largo de tres meses en la publicación impresa.

Carlos Otto (E1), considera que "para los medios nativos de papel, Internet es el espacio de experimentos para ver si los contenidos nuevos funcionan. Y si funcionan, van también al papel". Compartiendo esta idea y con los resultados obtenidos se verifica dicha teoría, aunque en el caso de ABC ni siquiera llega al papel.

En el caso del diario Expansión, los resultados comparativos entre medio impreso y online son los siguientes:

\section{Gráfico $n^{0}$ (6). Noticias Expansión 2013 por formato.}
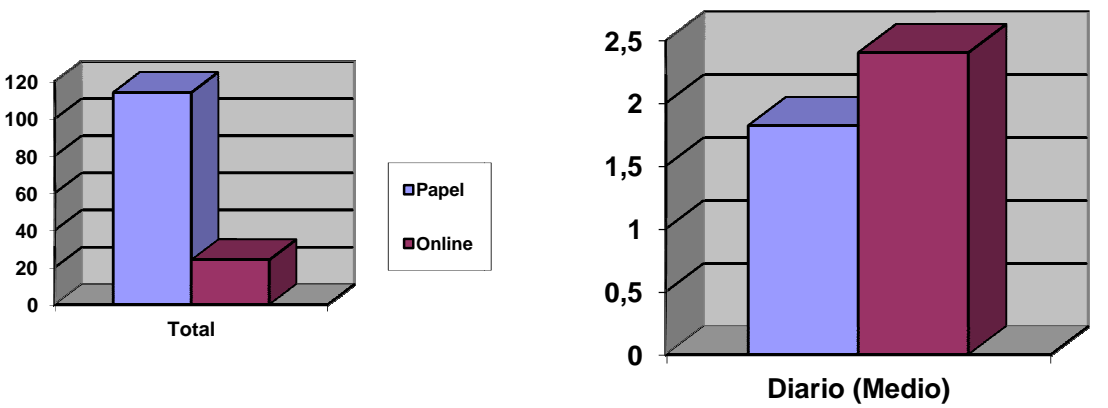

$$
\begin{aligned}
& \text { 口Papel } \\
& \text { 口Online }
\end{aligned}
$$

Fuente: elaboración propia.

Tras insertar la palabra "emprendedores" delimitada por las mismas fechas que en el periódico $\mathrm{ABC}$, el resultado de informaciones, sobre el tema en cuestión, con esta búsqueda es de 24 en los 10 días. La media de noticia diaria es mayor en el caso del online, aunque, en este caso, la diferencia es menor respecto al diario generalista.

Repetir, que esta comparativa no es completa del todo pues sólo está realizada a través del motor de búsqueda de Expansión. Aún así, ya los resultados delimitan que en los diarios online se publican más informaciones que en el medio impreso.

Para ver la posible repercusión que ha podido tener el proyecto de ley de emprendedores (que tuvo su mayor "bombo" en mayo, ya que estaba pretendido aprobarse desde el 26 de abril (Ruiz, J., 2013: Web) y tras un aplazamiento se fue conociendo la mayor información sobre ésta en mayo) analizaremos ambos medios en noticias clasificadas al mes.

Tabla no (9). Número de informaciones por mes en 2013.

\begin{tabular}{|l|l|l|l|}
\hline Periódico & Marzo & Abril & Mayo \\
\hline Expansión & 35 & 32 & 46 \\
\hline ABC & 5 & 5 & 7 \\
\hline
\end{tabular}

Fuente: elaboración propia. 
En el caso del diario Expansión se nota más la diferencia entre los dos meses anteriores y mayo, debido a que hay más cantidad de información.

La publicación en mayo prevalece sobre marzo y abril, y se explica que la mayor cantidad de información sobre la ley de emprendedores se produce en este mes. A pesar de ello, la diferencia no es tan significativa y esto se puede explicar con el siguiente epígrafe sobre la inclusión de las informaciones en las diferentes secciones y en las diferentes temáticas, que se verán más adelante.

Tras haber analizado estos datos, vamos a pasar a disgregar más aún el estudio presentando las secciones dónde se alojan las informaciones.

A lo largo de este estudio, lo más relevante es el diario Expansión debido a que tiene una cantidad de noticias significativas y que puede llevar a unas conclusiones. Consecuentemente, se analizarán primero los años 2013 y después su correspondiente comparación con 2011 a partir de los siguientes apartados.

B) Secciones.

B.1. 1 Expansión en 2013:

En el 2013, el diario Expansión tiene una sección denominada "Emprendedores y empleo" de tan sólo una página, por lo que una noticia diaria está asegurada. Lo relevante, en este caso, son el número de noticias que salen fuera de esta apartado, pues ya tendrían un sitio en éste.

Tabla $n^{0}$ (10). Número de publicaciones por sección en Expansión impresa 2013.

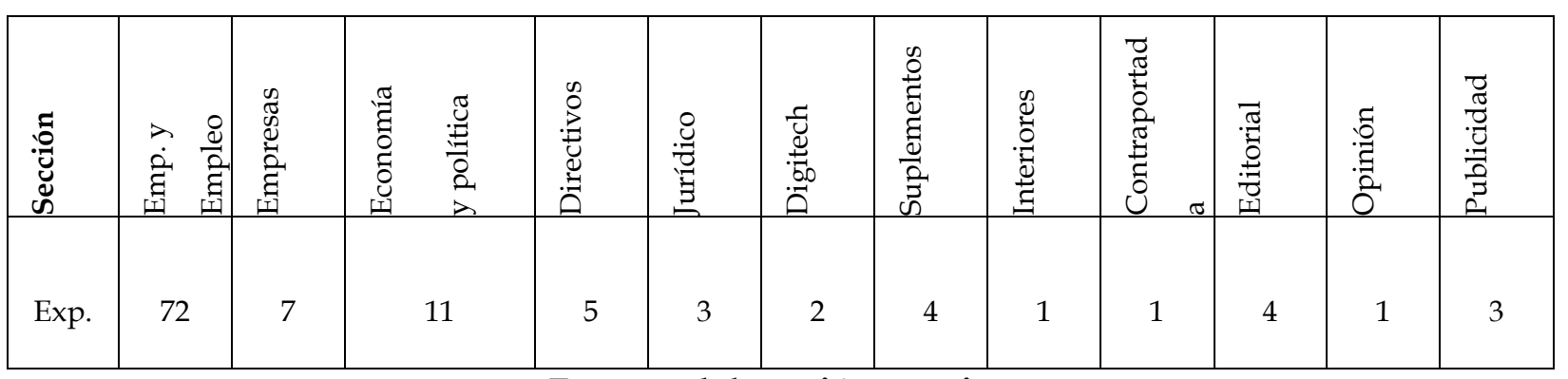

Fuente: elaboración propia.

Para ver más clara esta diferencia y la clasificación por sección, atendemos a los siguientes gráficos diferenciados por 2013 y 2011, ya que incluyen diferentes secciones: 
Gráfico n (7). Secciones Expansión 2013.

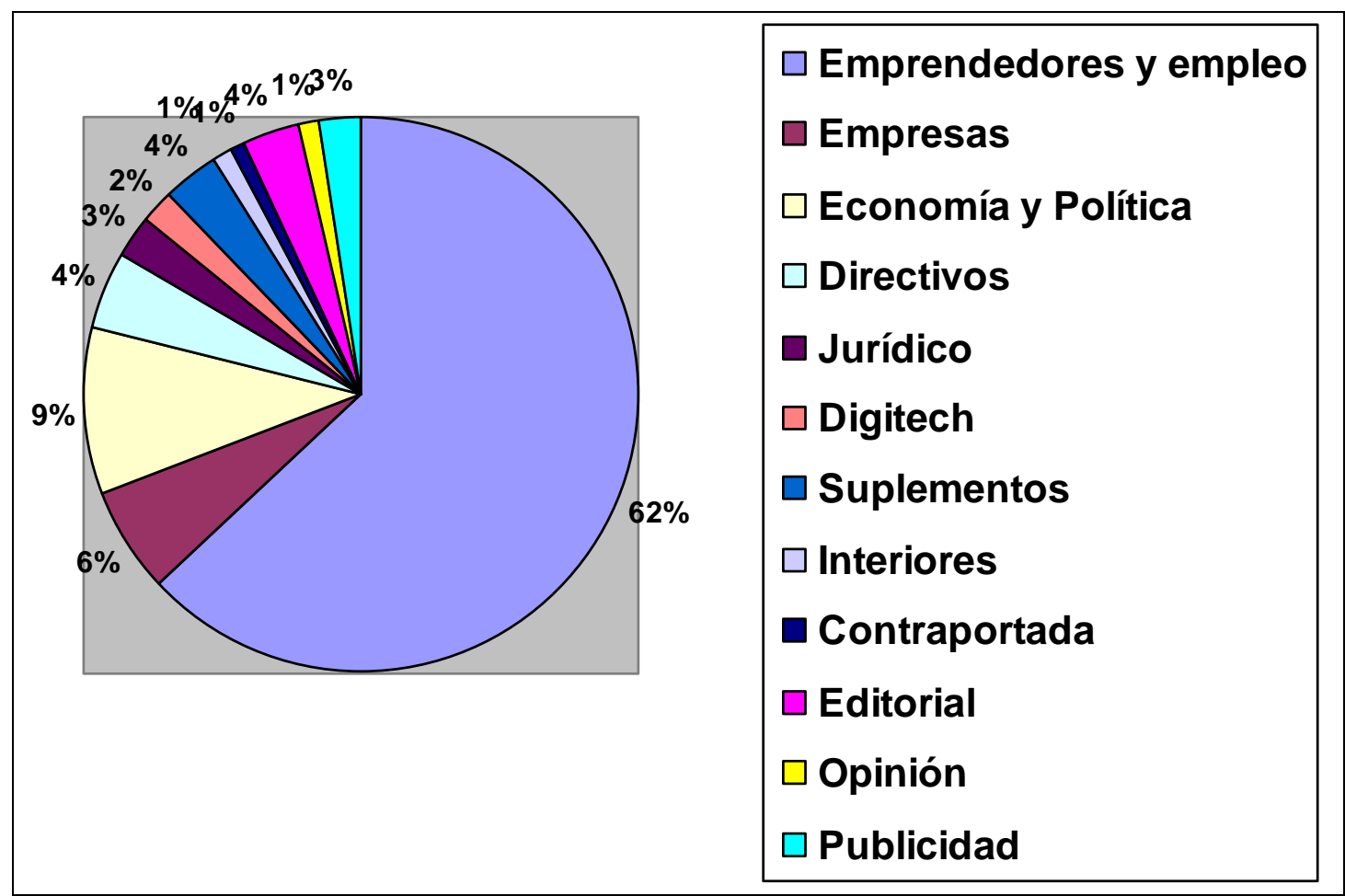

Fuente: elaboración propia.

En esta gráfica, podemos observar cómo la mayoría de la información, más en concreto el 62\%, pertenece a la sección "Emprendedores y Empleo", como es lógico, y un $38 \%$ se extrae del resto de secciones, lo que es destacable.

De este anterior gráfico se puede destacar la inclusión de 4 editoriales sobre el emprendimiento. El editorial se define como "un texto que constituye la opinión de la empresa periodística sobre los temas más importantes de la actualidad, especialmente políticos y económicos. En otros términos, es la expresión institucional que marca la línea ideológica del medio" (Di Palma, 2010: 79).

Es reseñable por lo tanto que de un total de 64 días, se hayan dado hasta cuatro editoriales sobre este tema. Los titulares son:

- La administración frena a los emprendedores

- Nuevas facilidades para emprendedores

- La oportunidad de la ley de emprendedores

- Los emprendedores no se libran de la burocracia

La última y penúltima editorial se refiere a la ley de emprendedores. Sin embargo, las otras dos no aluden a dicha norma. No es un dato desmesurado, pero es destacable que hasta 4 editoriales fueran publicadas durante estos tres meses. Otro de los resultados a destacar del anterior análisis es que encuentran hasta 11 secciones diferentes que incluyen noticias sobre emprendimiento, siendo sólo tres las que cubren una información. 
B.1.2.) Expansión en 2011

Por su parte, en el año 2011, obtenemos los siguientes resultados:

\section{Gráfico n (8). Secciones Expansión 2011.}

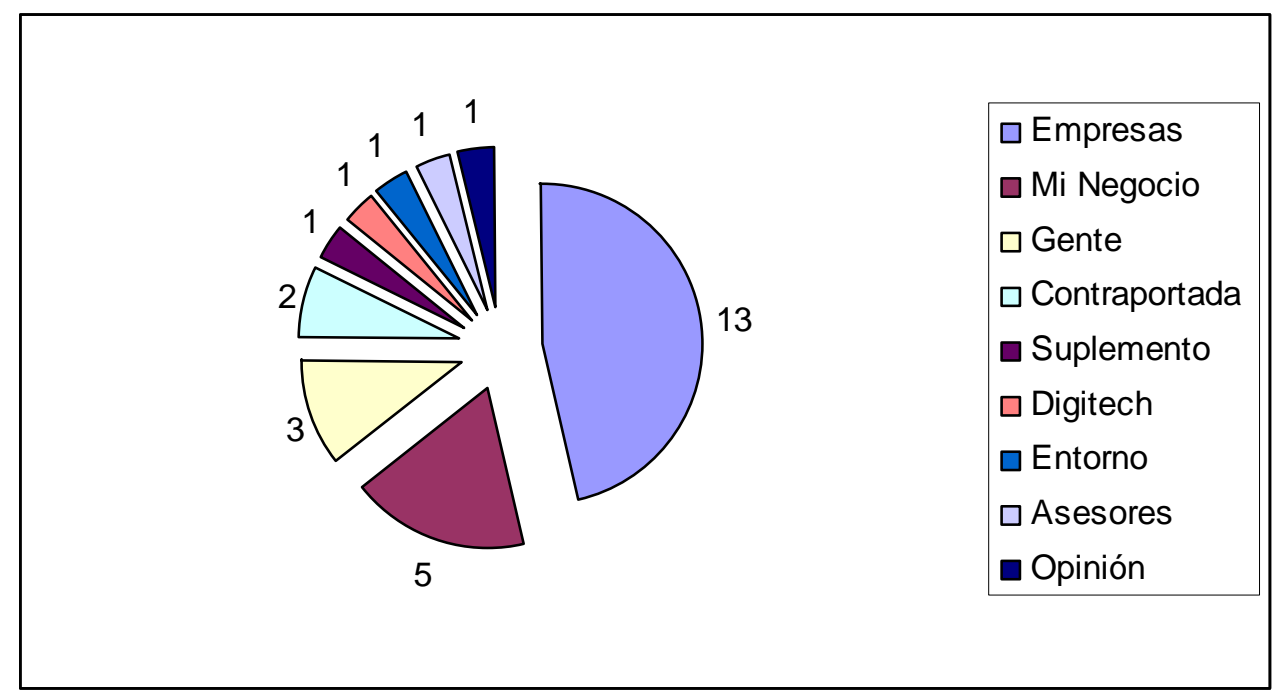

Fuente: elaboración propia.

En este caso, de las 28 informaciones analizadas encontramos la mayoría de éstas en la sección "empresas" con hasta 13 siendo el 46,5\% de las publicaciones pertenecientes a este espacio. Por detrás, cuya sección ya no existe, "Mi Negocio" con 5, “Gente" con 3, "Contraportada" 2 y en el resto solamente una vez.

En este caso, también se puede apreciar que la información sobre emprendedores, aunque mucha menor que en 2013, también se reparte en diferentes espacios, hasta en 9 diferentes.

B.1.3.) Expansión impreso vs. Online en 2013.

La comparación con el medio online con los resultados obtenidos es de:

Gráfico $n^{\circ}$ (9). Secciones Expansión 2013 por formato.

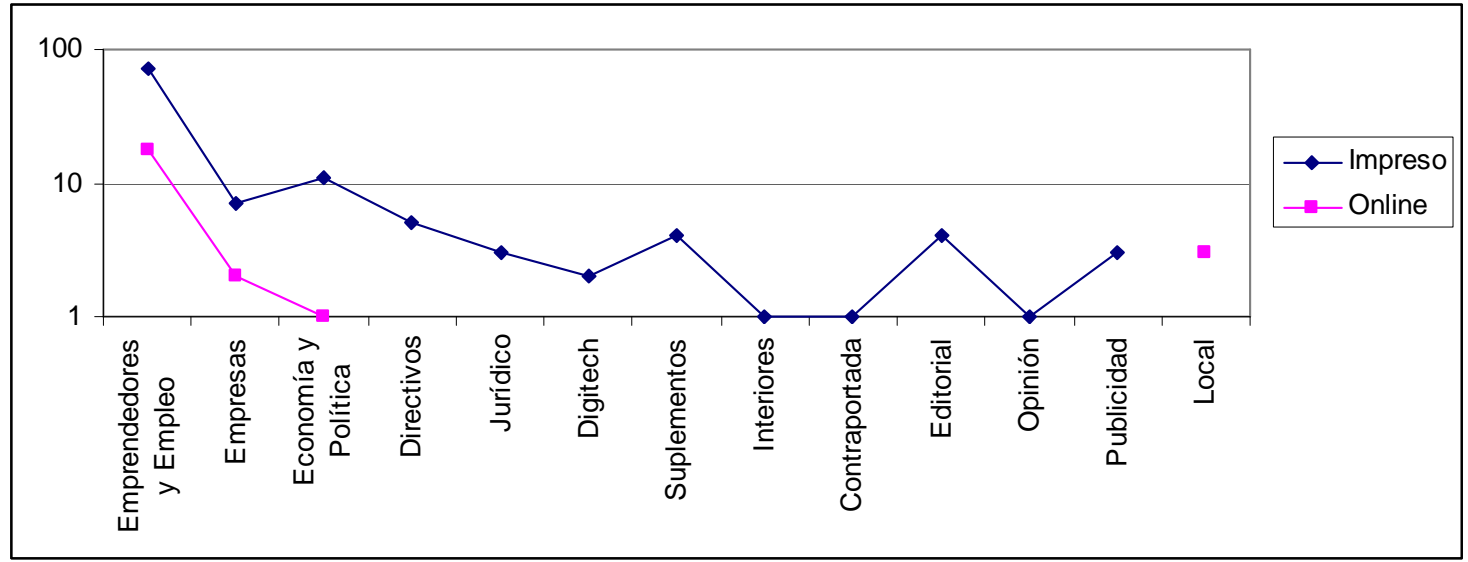

Fuente: elaboración propia. 
Podemos observar cómo en el caso del diario online, sólo encontramos cuatro tipos de espacios dónde se albergan las informaciones, y la mayoría se engloban en "Emprendedores y Empleo" con hasta 18 de las publicaciones, por detrás se encuentran "Empresas" con 2, "Economía y Política" con 1 y "Local” 3.

La conclusión principal que se puede derivar es que:

- Aparentemente en el diario online la mayoría de informaciones se engloban en la sección Emprendedores y Empleo. Esta conclusión, si el análisis fuera más exhausto, podría llevarnos a deducir a que la sección de "Emprendedores y Empleo" se queda pequeña en el caso del diario impreso.

\section{B.2.1.) ABC en 2013.}

Por otro lado, en el caso del diario generalista en 2013, si analizamos la sección donde la información aparece:

Tabla $n^{0}$ (11). Número de publicaciones por sección en ABC impresa 2013.

\begin{tabular}{|c|c|c|c|c|c|c|c|c|}
\hline 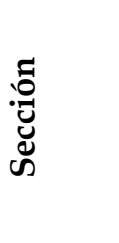 & 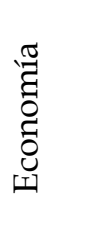 & 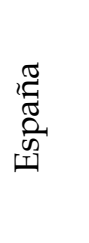 & 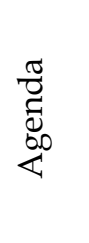 & $\begin{array}{l}\frac{\pi}{\pi} \\
\frac{\pi}{0} \\
0 \\
0 \\
\tilde{0} \\
0 \\
0\end{array}$ & $\begin{array}{l}\frac{\pi}{\vec{B}} \\
\frac{\pi}{\Sigma} \\
\sum^{\pi}\end{array}$ & 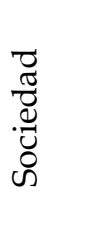 & 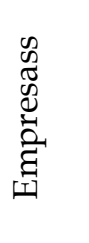 & $\begin{array}{l}\frac{0}{\pi} \\
\frac{\pi}{0} \\
\frac{0}{0} \\
0 \\
0\end{array}$ \\
\hline $\mathrm{ABC}$ & 5 & 2 & 2 & 1 & 3 & 2 & 1 & 1 \\
\hline
\end{tabular}

Fuente: elaboración propia.

Se puede observar que la mayoría de información en este caso se encuentra en la sección "Economía" con hasta 5, seguido por la información local de Madrid con 3. A continuación encontramos a "España", "Agenda" y "Sociedad" con 2 y una información en el caso de "Empresas", "Contraportada" y "Publicidad".

Asimismo, cómo en el caso del medio especializado había hasta 4 editoriales, en este caso ni siquiera se hace una mención por parte de la línea editorial.

B.2.2.) ABC impreso 2011.

En el caso de 2011, sólo encontramos cinco informaciones y se encuadran en las siguientes secciones:

Tabla $n^{0}$ (12). Número de publicaciones por sección en Expansión impresa 2011.

\begin{tabular}{|l|c|c|c|}
\hline Sección & Economía & Sociedad & Contraportada \\
\hline ABC 2011 & 2 & 2 & 1 \\
\hline
\end{tabular}

Fuente: elaboración propia.

En este caso, al ser tan escasa información pocas conclusiones se pueden extraer. 
B.2.1. ABC impreso vs. Online en 2013.

Si hacemos la comparación con la publicación online, obtenemos los siguientes resultados:

Gráfico $n^{0}$ (10). Secciones ABC 2013 por formato.

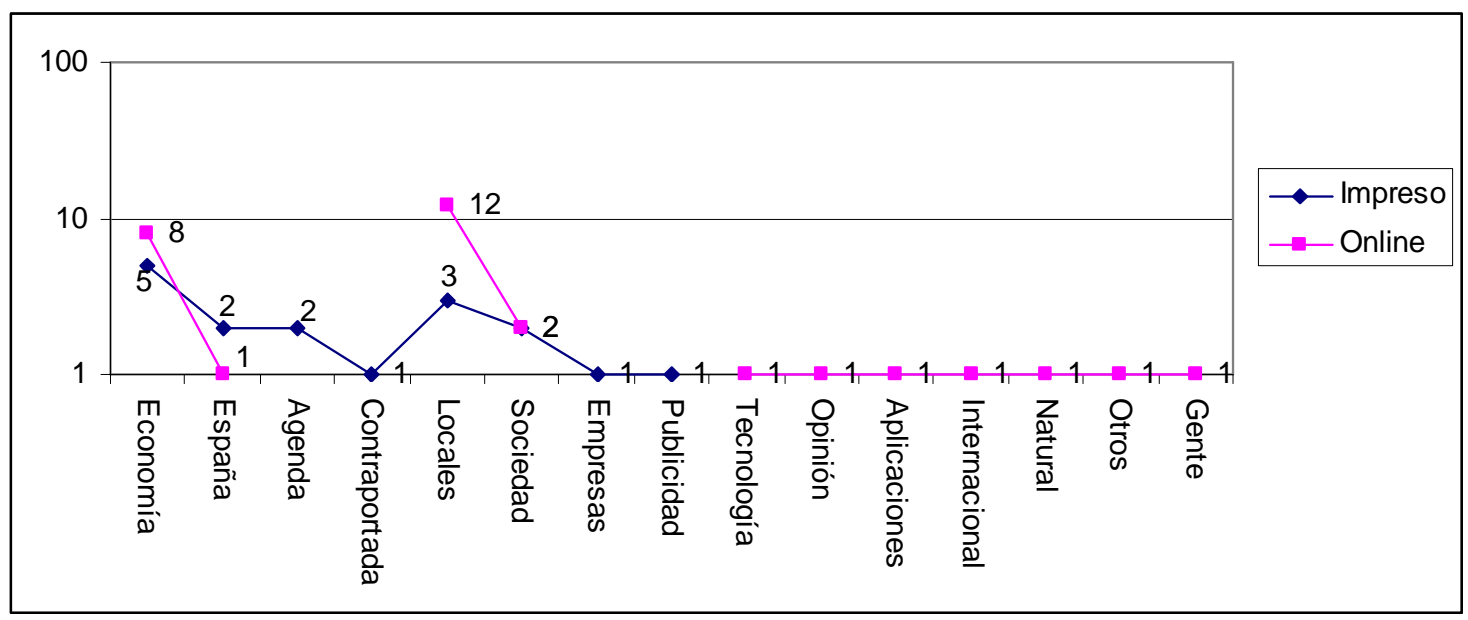

Fuente: elaboración propia.

Podemos observar que la información online también se abre a instalarse en diversas secciones, más concretamente en hasta 11 diferentes.

Se pueden apreciar dos conclusiones:

- En el medio online el tema del emprendimiento entra en muy diversas secciones, más concretamente hasta en 11 secciones diferentes respecto a las 8 del diario impreso, siendo también un lugar muy variado.

- En las secciones locales de provincias, es un tema bastante utilizado en el medio online.

Carlos Otto (E1) indica que esta información está teniendo mayor relevancia en medios económicos que en generalistas, pero a pesar de eso:

En los generales cada vez más, aunque aún están anclados en contar solo las historias de éxito: están fascinados con el chavalito que, con 17 años, programa una aplicación y se la vende a Google por 17 millones de euros apenas unos meses después. Saben de sobra que ese no es un periodismo responsable, pero las visitas mandan. Y ese tipo de artículos arrasan. En cuanto a los económicos, siempre han hablado sobre emprendimiento, aunque ahora ven que, los contenidos que antes nadie visitaba, ahora los lee todo el mundo. Por suerte, los económicos son más rigurosos y tienen un planteamiento más serio.

Siguiendo esta opinión, tras analizar la cantidad de información y las posteriores secciones dónde aparecen y la diversidad de éstas sobre el indicador noticioso, pasamos a detallar sobre qué se publica. Verificar como así indica Otto, si los casos de éxito son el hecho noticioso a la orden del día o si por el contrario existe diversidad temática que ofrece información de utilidad a los emprendedores en particular y a la sociedad en general. 
C) Tipo de información.

Para proceder a esta diferenciación se ha segregado las informaciones en las siguientes temáticas:

- Historias sobre emprendedores: relatos sobre emprendedores, startups, casos de éxito... en general, historias personales.

- Consejos para emprendedores: reportajes, análisis y artículos que aportan información útil para actuales o futuros emprendedores sobre cómo financiar una empresa, dar visibilidad a ésta...

- Oportunidades de negocio: reportajes, análisis sobre mercados emergentes dónde poder emprender.

- Actualidad: información relacionada con el emprendimiento de actualidad, como por ejemplo cursos, conferencias, concursos, leyes, normas...

- Ley de Emprendedores: información relacionada con la ley de emprendedores aprobada el 26 de julio.

C.1) Tipos de información 2013.

Gráfico n (11). Tipología de informaciones en 2013.

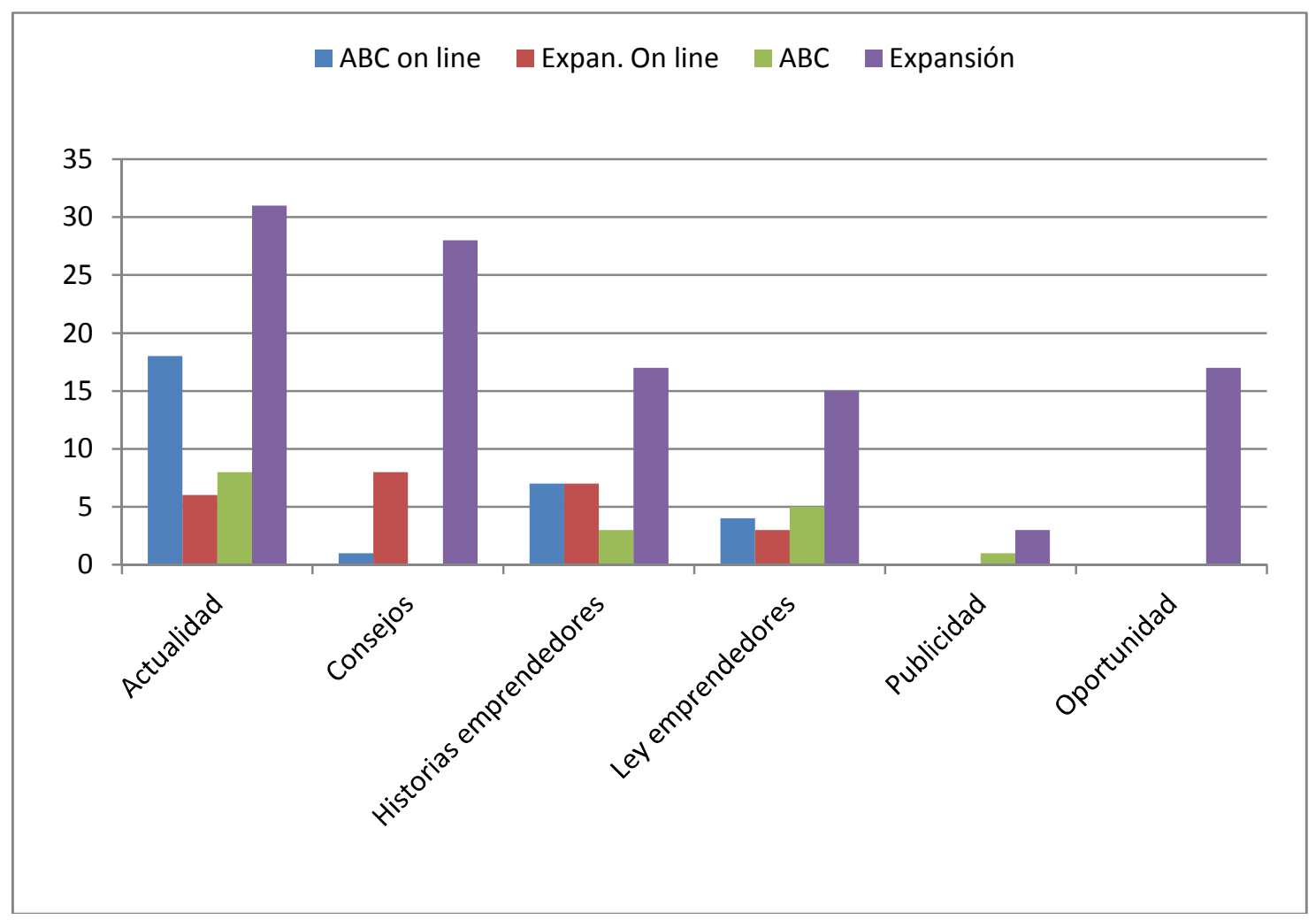

Fuente: elaboración propia.

Es muy significativo que las "historias de emprendedores", que son aquellos casos de éxito personales, se releguen hasta la tercera posición del diario Expansión y a la segunda en el $\mathrm{ABC}$ en el caso del formato impreso. 
A pesar de que no es equiparable la comparación en el formato online por la cantidad/número de días analizados, los resultados son similares al formato impreso.

Para extraer conclusiones, vamos a diferenciar por diarios:

I. Expansión.

a. El mayor número de publicaciones se encuentra en el capítulo "Actualidad", seguido muy de cerca por los "Consejos". Este hecho implica que este diario especializado aborda el asunto de los emprendedores más allá de simplemente casos de éxito o, en referencia a la ley de emprendedores. Una segunda visión de este resultado, es que los temas de actualidad sobre emprendimiento se suceden con mucha frecuencia, lo que induce a que existen acciones, sucesos... por parte de los implicados en este proceso económico.

b. El periódico dedica bastante espacio a "Consejos" y "Oportunidad de negocio", ofreciendo información sobre modos de optimización de los negocios a través de técnicas, análisis, recursos... y mercados hacia los que poder dirigirse, que ofrece, de esta manera, una herramienta útil para los emprendedores pero de cuestionable valor periodístico.

c. En una misma equiparación, encontramos a las "historias de emprendedores" y a la "ley de emprendedores" lo que induce a que la norma ha tenido una repercusión considerable, cómo se ha citado anteriormente al señalar que atesoraba hasta cuatro editoriales.

d. Por último, es destacable que haya hasta tres artículos publicitarios sobre productos relacionados con emprendimiento, (en este caso, un "Libro para emprendedores" creado por el mismo diario) con lo que se concluye un interés por parte del periódico sobre esta información.

II. ABC.

a. Teniendo en cuenta que el número de informaciones es mucho menor al anterior, destacar que el número de noticias más repetidas es sobre "actualidad" por encima de la "ley de emprendedores". Este dato indica, igualmente que en el caso anterior, que la información actual sobre emprendimiento se utiliza por encima, incluso, de la actual norma que ha estado durante meses en debate político y consecuentemente público.

b. En el caso del $\mathrm{ABC}$ no se ofrece en ningún momento ni "consejos" ni "oportunidades de negocio" lo que señala que, únicamente, tratan información de actualidad.

c. A modo de conclusión, indicar que en este caso la información actual se antepone sobre los casos de éxito.

Tras analizar las secciones y observar la amplia oferta que ofrece el emprendimiento en éstas y la también diversidad de temáticas y que no se queda sólo encorsetadas en historias sobre emprendedores o, lo que es lo mismo, casos de éxito, pasamos a ver qué tipo de informaciones nos encontramos y sus consecuentes implicaciones.

C.2.) Tipos de información 2011 - 2013.

En el caso de 2011, encontramos las siguientes tipos de informaciones en ambos diarios: 
Gráfico n ${ }^{0}$ (12). Tipología de informaciones en medio impreso en 2011.

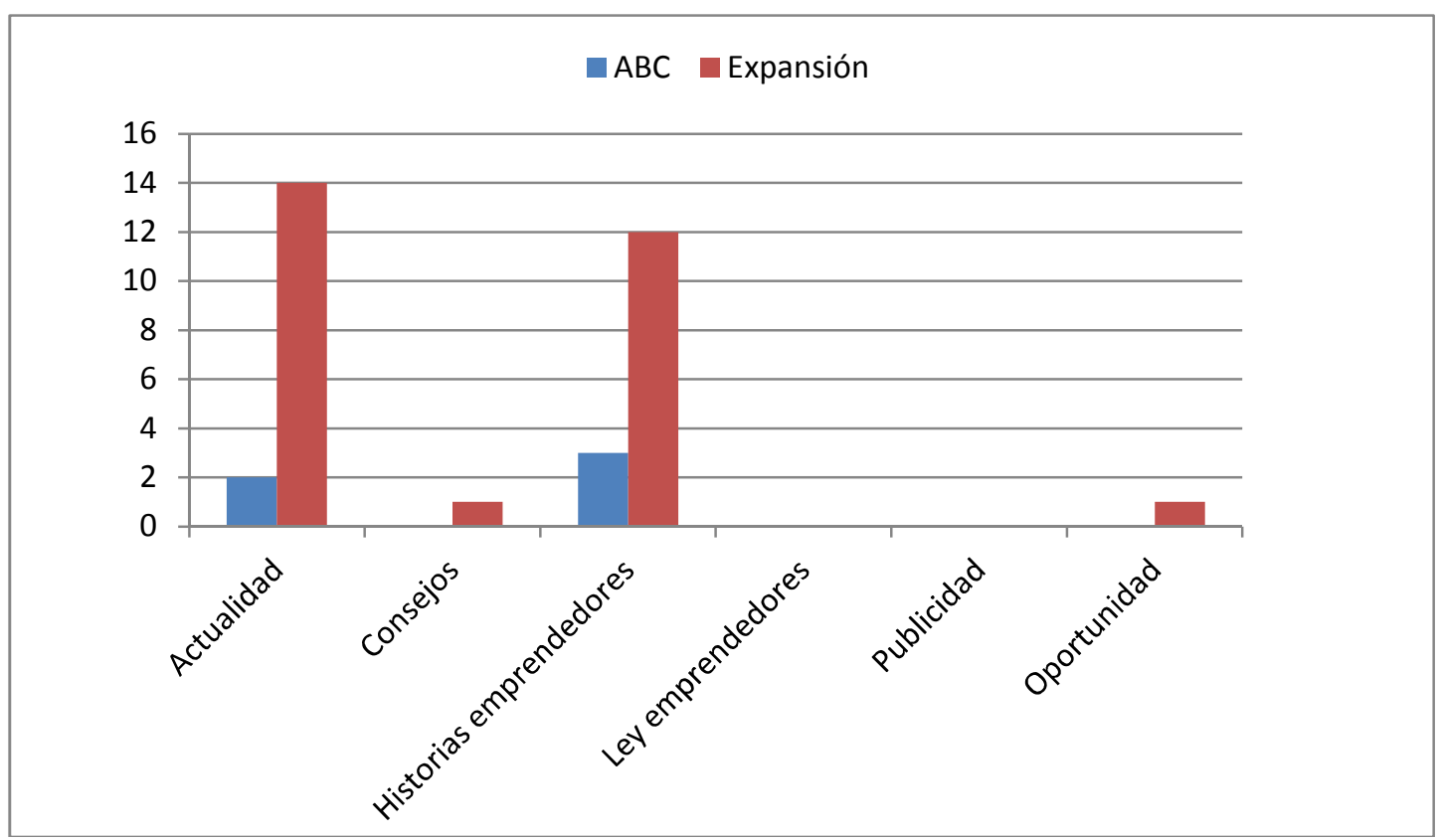

Fuente: elaboración propia.

Podemos observar que en este caso la diferencia entre actualidad y las historias de emprendedores no se encuentran tan alejadas en el caso del diario Expansión (14 sobre hechos noticiosos del momento frente a 12 relatos sobre casos de éxito/experiencias de emprendedores). En el caso del $A B C$, incluso se da una información más sobre historias que sobre actualidad.

Si lo comparamos con el año 2013 y vemos los totales la diferencia se puede hacer más apreciable: 
Gráfico $n^{0}$ (13). Tipología de informaciones en medios impresos en 2011-2013.

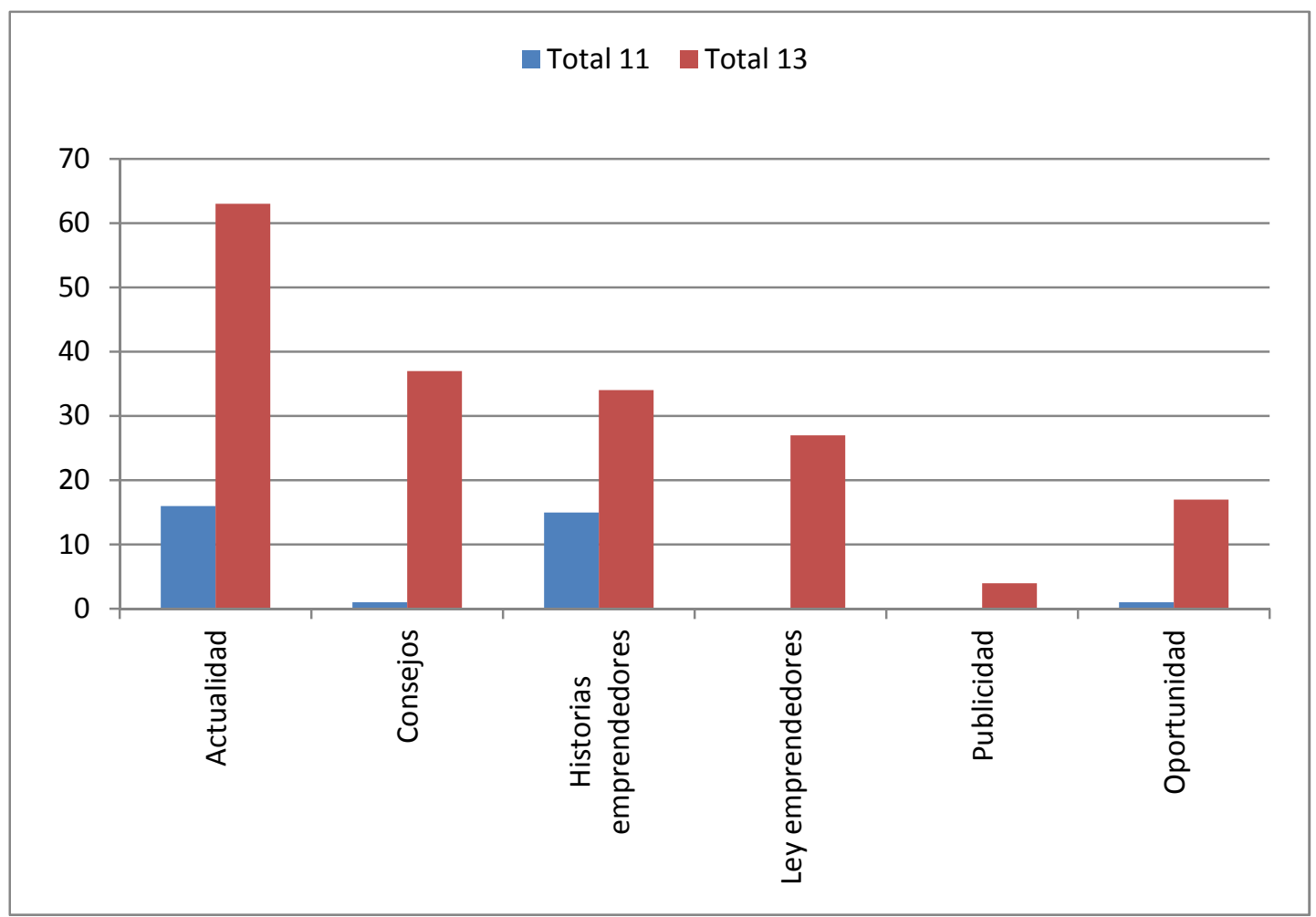

D) Género.

Fuente: elaboración propia.

D.1. Género en 2013.

Gráfico $n^{0}$ (14). Género de las informaciones en 2013.

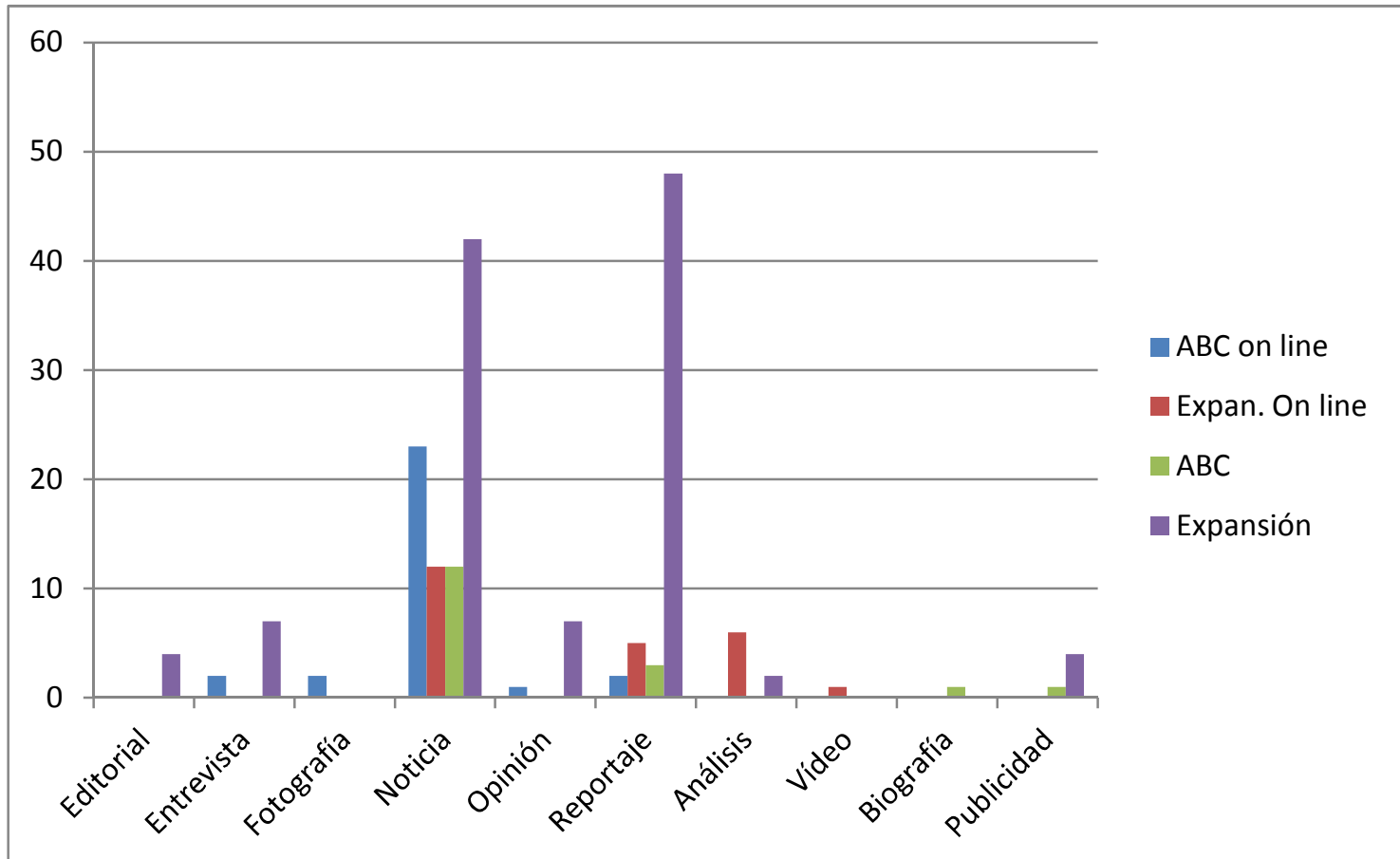

Fuente: elaboración propia. 
Podemos observar que, en conjunto, la información que más destaca es la noticia por encima, seguido muy de cerca, por el reportaje, utilizado en este caso más significativamente por parte del periódico Expansión.

En este caso, son destacables varios aspectos a analizar sobre todo en el caso de la edición impresa, pues este apartado es más relevante en este medio debido a la cantidad de informaciones como se ha citado anteriormente:

-En conjunto, teniendo en cuenta a ambos medios, el tipo de información más utilizada es la noticia acorde con que la temática más utilizada, que como se ha señalado anteriormente, es la actualidad.

-Sin embargo, no muy lejos de esta se encuentra el reportaje. Echevarría (2011: 20) lo define como el género periodístico más completo y señala que "sirve para completar, ampliar, profundizar, para dar contexto a una noticia... para descubrir qué hay detrás de una noticia". El diario Expansión utiliza este género como medio más utilizado, aunque muchos de éstos se podrían denominar "falsos reportajes", ya que, incluyen las características de éstos pero se quedan entre un reportaje y una crónica, sobre todo utilizados en la temática de "consejos". Grijelmo (1997: 58) explica que el reportaje "es un texto informativo que incluye elementos noticiosos, declaraciones de diversos personajes, ambiente, color, y que fundamentalmente, tiene carácter descriptivo" $\mathrm{y}$, por su parte, Salcedo (2005: 89) utiliza al teórico Vivaldi para definir la crónica como "una información interpretativa y valorativa de los hechos noticiosos". Algunas de las informaciones señaladas incluyen ambas características, pero se ha optado definitivamente por señalarlas cómo reportaje, pues están más cerca de éste. A pesar de todo esto, el reportaje es el género más utilizado seguido de la noticia en el diario Expansión.

-Es reseñable, asimismo, que por parte del diario especializado la diversidad de géneros es más amplia y que seguido de la noticia y el reportaje se encuentran la opinión y la entrevista. Es significativo que estos dos géneros se utilicen, pues se trata de informaciones que pretenden dar una visión más subjetiva a través del conocimiento o de la experiencia. 
D.2.) Género 2011-2013.

Gráfico n ${ }^{0}$ (15). Género de las informaciones en medios impresos en 2011.

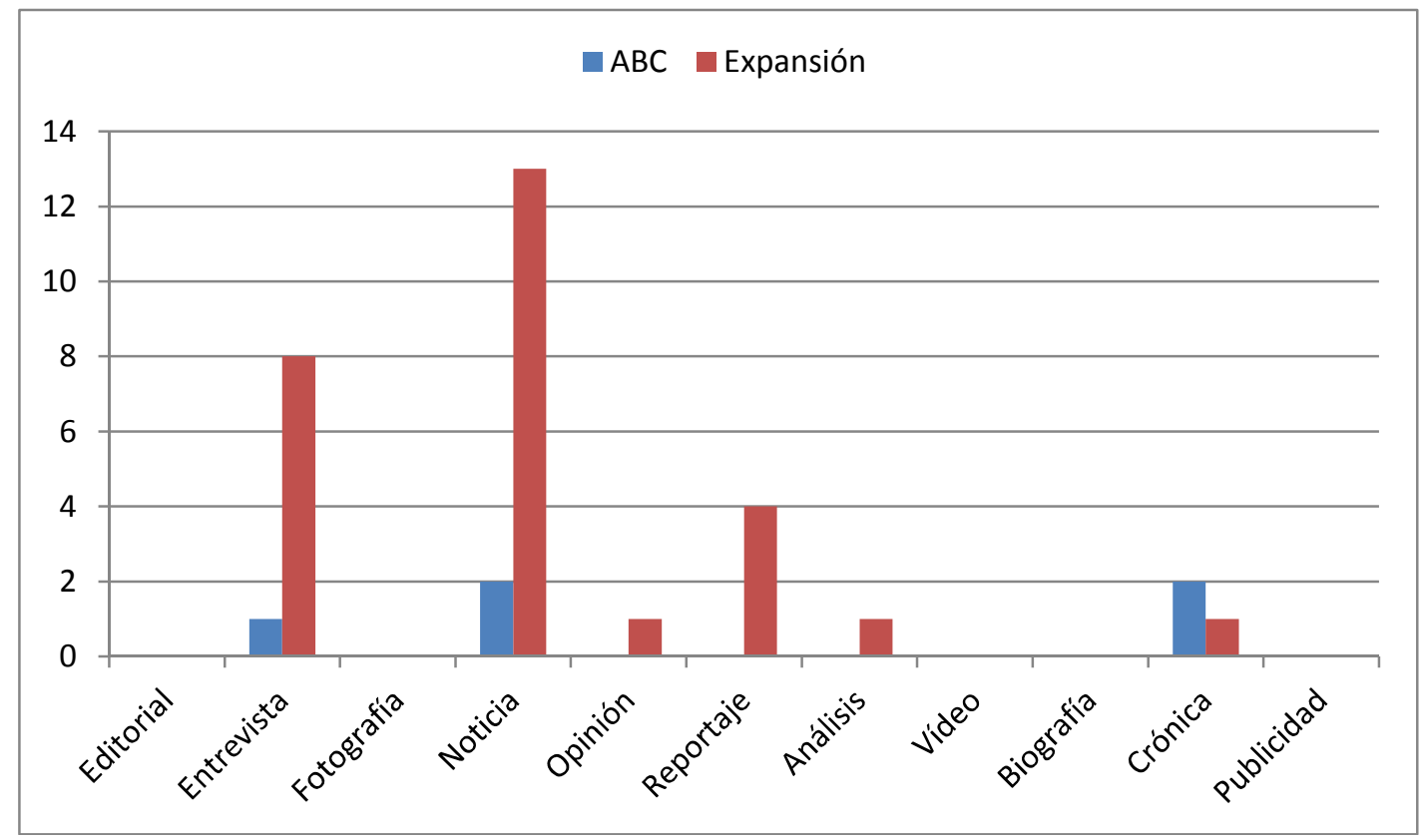

Fuente: elaboración propia.

Podemos observar que en este caso la mayor de la información también se corresponde con el género de la noticia, hasta con 13 publicaciones diferentes en el caso del diario Expansión y 2 en el caso del ABC. A continuación, se encuentra la entrevista de manera más significativa, en el periódico especializado, respecto a 2013, con hasta 8 informaciones.

El reportaje, que en 2013 para Expansión era el género más utilizado, se encuentra en la tercera posición en este caso.

Para observar la diferencia más claramente con 2013, en el caso impreso que es el extrapolable, se presenta el siguiente gráfico: 


\section{Gráfico $n^{0}$ (16). Género de las informaciones en medios impresos 2011 y 2013.}

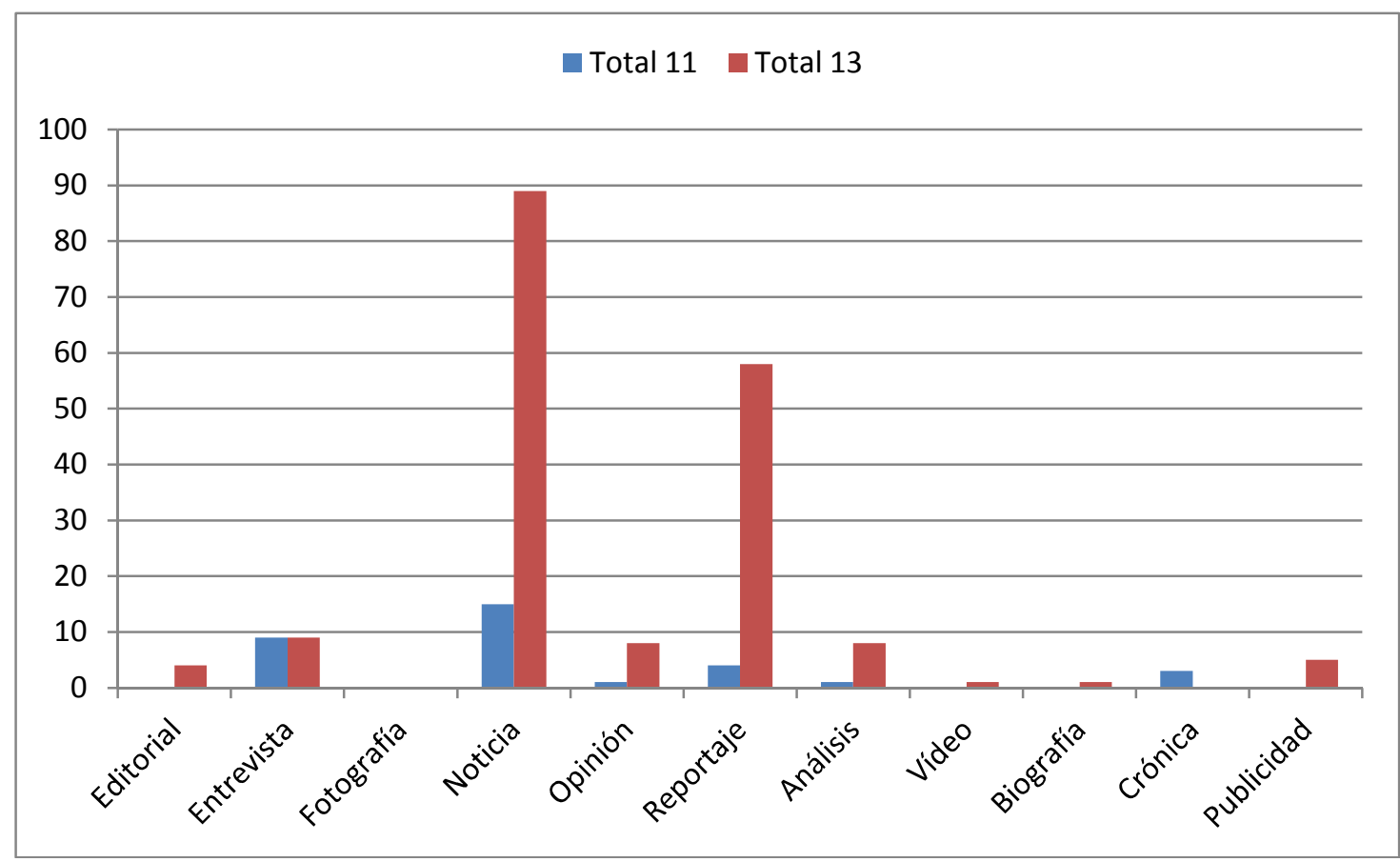

Fuente: elaboración propia.

E) Columnas.

\section{E.1.) Columnas en 2013.}

Por otro lado, vamos a observar el número de columnas que tienen las informaciones analizadas hasta ahora, en este caso, lógicamente, exclusivamente en el formato papel.

La media en ambos diarios está entre tres y cuatro columnas, aunque también es relevante que en Expansión hasta en 23 ocasiones llegue hasta 5 columnas ofreciendo una información más amplia.

Por otro lado, también es reseñable que hay muy pocos reportajes extensos en ambos diarios, los cuáles son, concretamente, sobre la Ley de Emprendedores, llegando hasta 11 y 12 columnas en $\mathrm{ABC}$ y Expansión, respectivamente.

Por último, en ambos periódicos existen informaciones con pocas columnas aunque no es lo que preside. 
Emprendimiento-redes sociales-prensa-mediatización

Gráfico nº (17). Columnas en las informaciones en 2013.

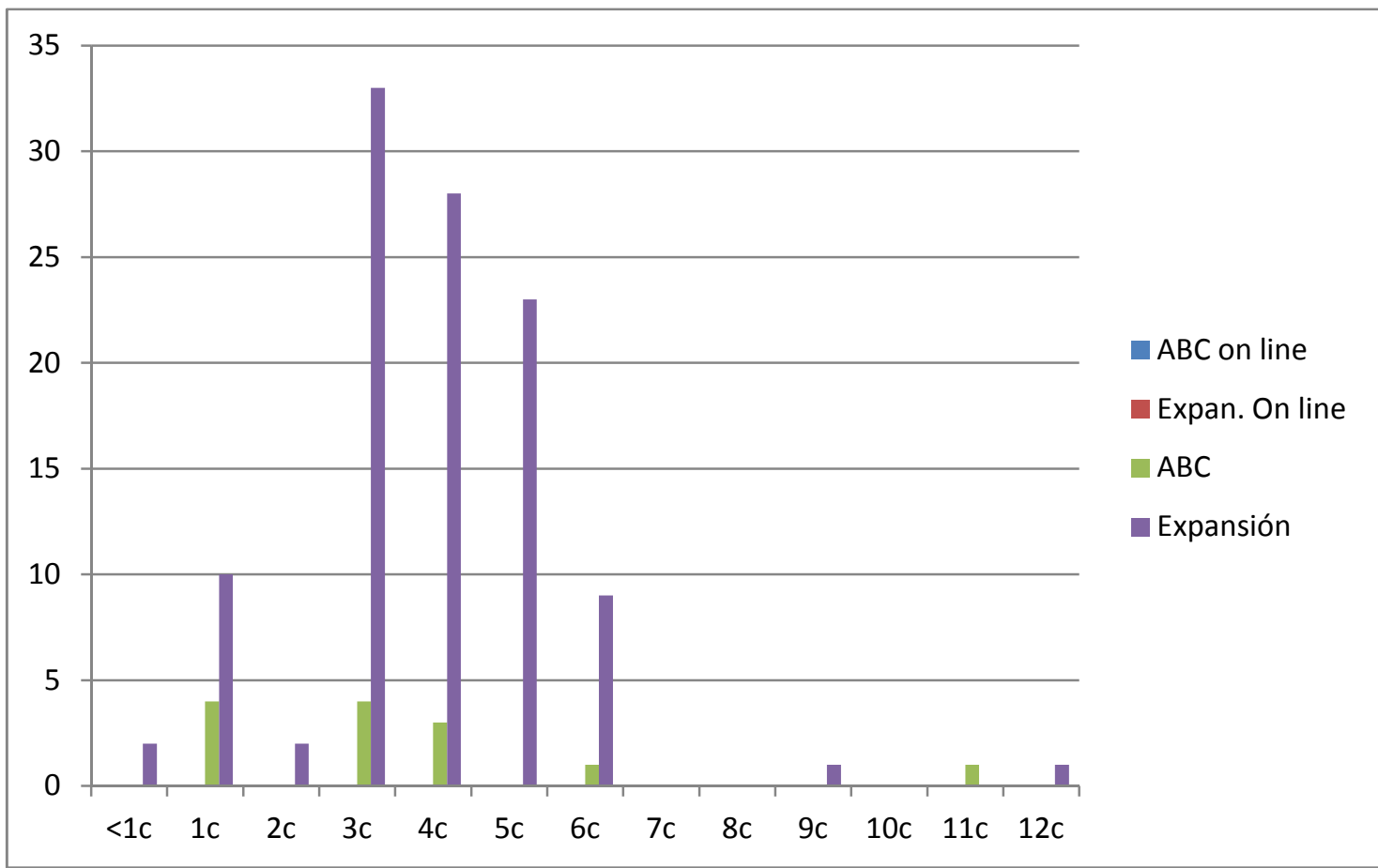

Fuente: elaboración propia.

E. 2.) Columnas en 2011-2013.

Se puede observar a través del siguiente gráfico como no existe apenas diferencia respecto a 2013, en el total de ambos diarios, en este análisis:

Gráfico n ${ }^{0}$ (18). Columnas en las informaciones en medios impresos 2011 y 2013.

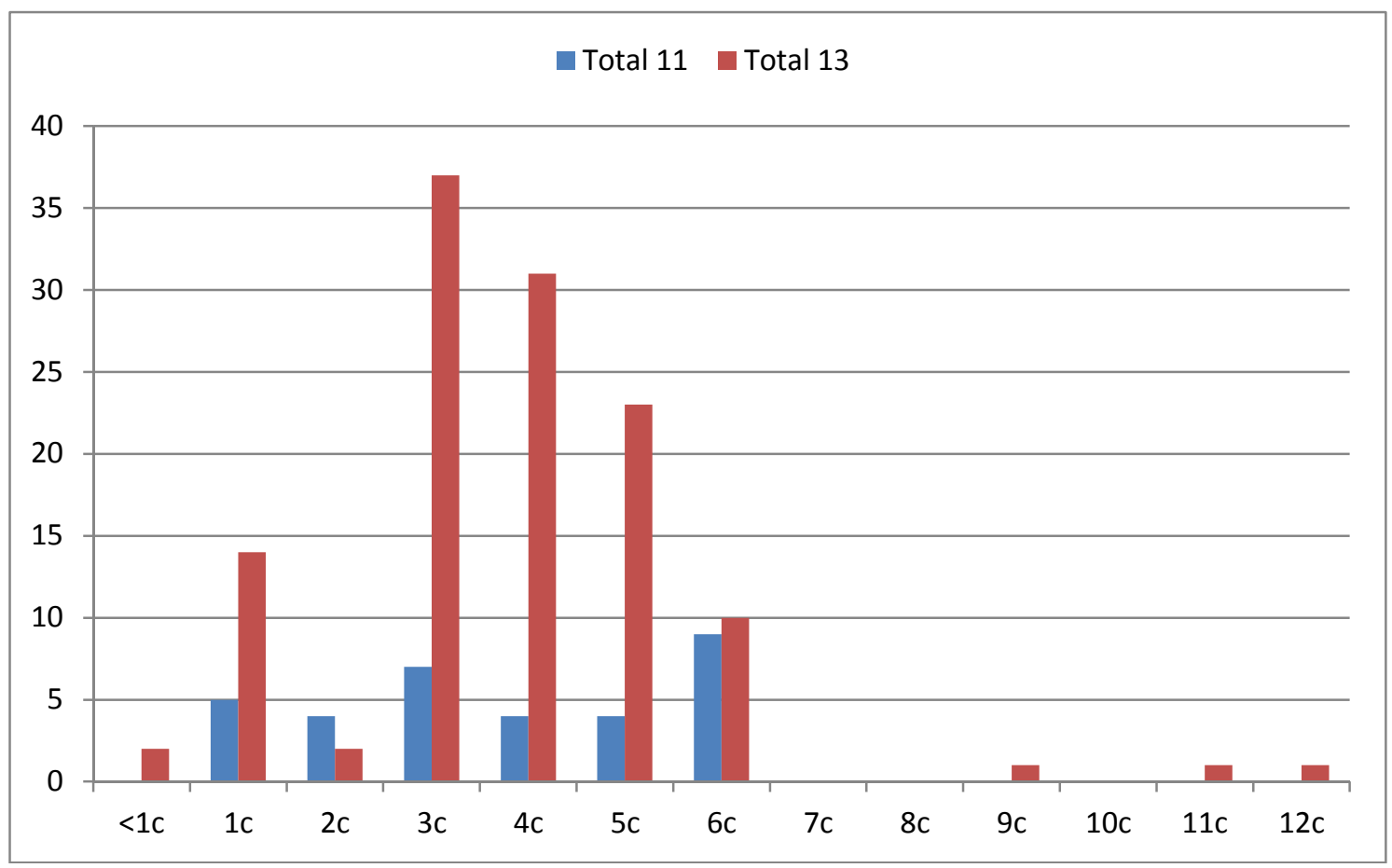




\section{Fuente: elaboración propia.}

La única diferencia que se encuentra respecto a 2013 es la información de hasta 6 columnas, más extensa, que preside en el año 2011.

F) Firma.

\section{F.1. Firma en 2013.}

Cómo último elemento a analizar, pasaremos a verificar que el emprendimiento es una información es constante crecimiento pero que no precisa, o eso parece, de periodistas especializados únicos para realizar esta cobertura.

En este caso, se muestra simplemente el caso de los medios impresos ya que son valores absolutos y no orientativos. La siguiente representación muestra la cantidad de firmantes de las informaciones:

Gráfico $n^{0}$ (19). Firmas en medios impresos 2013.

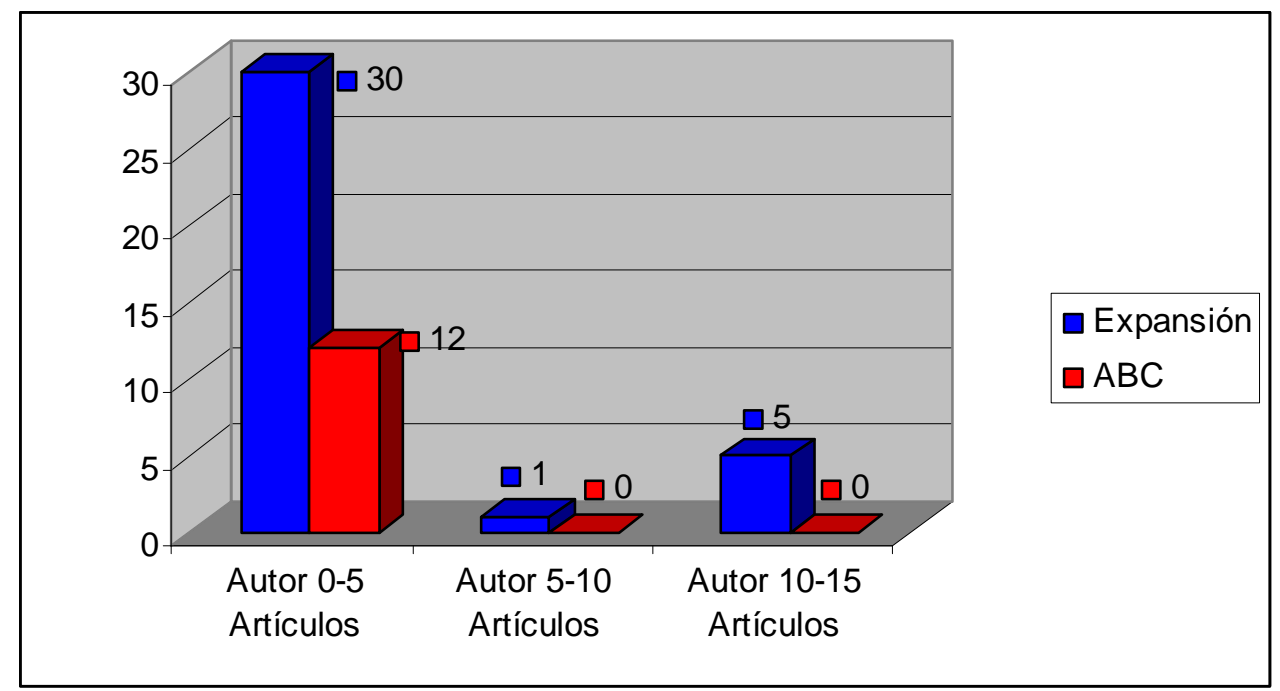

Fuente: elaboración propia.

Si diferenciamos por diarios:

-Expansión:

O Hay hasta 30 periodistas que realizan información sobre emprendimiento que no superan los cinco artículos en el tiempo analizado.

O Hay hasta 5 periodistas que realizan más de 10 informaciones sobre 64 días, por lo que se podría decir que son los "habituales" hacedores de esta información, aunque sin embargo, la diversidad es apabullante ya que hasta 36 profesionales llegan a publicar en su periódico sobre el tema en cuestión en torno 114 informaciones diferentes.

- ABC

O En el caso del diario generalista, la información que en su mayoría son temas de actualidad o sobre la ley de emprendedores las redactan periodistas diferentes, llegando a hasta 12 profesionales diferentes para 17 informaciones. 
F.2.) Firma 2011-2013.

Gráfico $n^{0}$ (20). Firmas e informaciones publicadas en medios impresos 2011 y 2013.

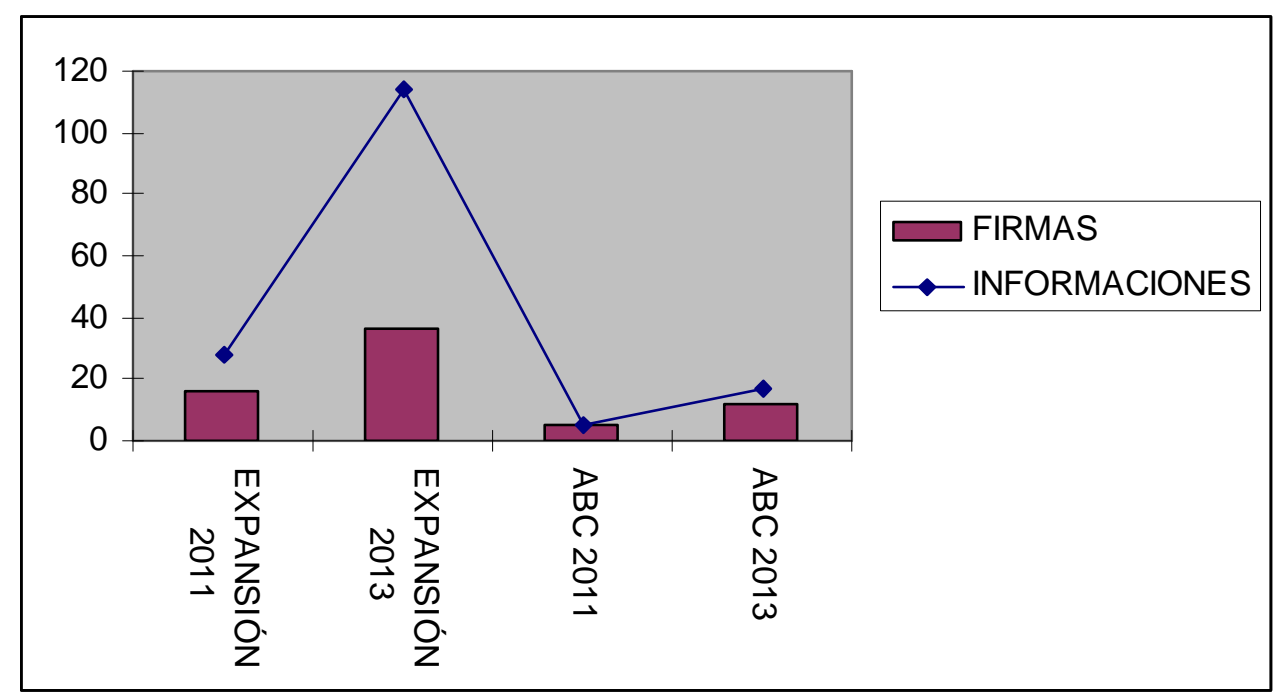

Fuente: elaboración propia.

Se puede ver cómo en este caso Expansión 2011, ABC 2011 y ABC 2013 comparten aproximadamente el mismo número de informaciones con diferentes autores.

Sin embargo, podemos observar como exclusivamente en el año 2013 en el diario Expansión existen más informaciones que autores diferentes de las publicaciones, por lo que se extrae que sólo en este caso los periodistas se encargan de publicar más de una o dos informaciones sobre el tema en cuestión.

\section{DISCUSIÓN}

Tras analizar el contexto en el que se mueve el emprendimiento, los resultados obtenidos de las técnicas empleadas y la comparativa realizada con los escasos estudios previos, podríamos afirmar que el emprendimiento se está tratando con una mayor dedicación en los medios de comunicación. En ellos, actualmente los medios impresos crean secciones y las televisiones crean programas sobre el tema en cuestión. Del mismo modo apuntan a que las redes sociales son una herramienta muy importante y útil para los emprendedores. Se pueden extraer las siguientes conclusiones respecto a las hipótesis propuestas previamente:

1. Respecto a la hipótesis 1, la información sobre emprendimiento ha aumentado muy significativamente, lo que ha reforzado positivamente que sea un tema de mayor calado en los medios de comunicación. Las redes sociales, asimismo, han contribuido positivamente en visibilidad y notoriedad para los emprendedores.

2. Respecto a la hipótesis secundaria $1^{\circ}$, la información especializada abarca el tema de manera mucho más significativa que la generalista. Ambos diarios analizados 
(Expansión y $\mathrm{ABC}$ ) han aumentado de manera muy considerable sus publicaciones en 2013 respecto a 2011.

3. Respecto a la hipótesis secundaria $2^{\circ}$, Internet ha permitido que a la información sobre emprendimiento se le dé una mayor cobertura respecto a la impresa.

4. Respecto a la hipótesis secundaria $3^{\mathrm{a}}$, la ley de emprendedores no ha influido significativamente en un incremento de cobertura sobre emprendimiento por parte de los medios.

Otras conclusiones significativas del estudio son:

5. La información más utilizada por los medios de comunicación sobre emprendimiento versa sobre temas de actualidad (cursos, conferencias, actos, financiación...), tanto en 2013 cómo en 2011; aunque se ve claramente incrementada la diversidad de tipologías (consejos, oportunidades de negocio...) en 2013.

6. La importancia del emprendimiento se puede visualizar al observar en el diario Expansión hasta cuatro editoriales en los tres meses analizados en 2013, siendo dos sobre la ley de emprendedores.

7. La noticia es el género más utilizado en general, lo que apoya la conclusión anterior.

8. Las dos anteriores conclusiones llevan a que el emprendimiento se esté tratando por parte de los medios más allá de los casos de éxito de emprendedores, que se veía más pronunciado en 2011, incluyendo información útil para los emprendedores.

9. La percepción de la sociedad de que se está cubriendo cada vez más información sobre emprendimiento es notable.

10. Tanto en el diario Expansión como en el diario $A B C$, el emprendimiento se engloba en diversas secciones, lo que delata que es un tema sencillo al que acudir.

11. Los emprendedores, que ya cuentan con un negocio (startup - empresa emergente), consideran que los medios (tanto especializados, generalistas como online) cubren información sobre emprendimiento con un nivel medio, no siendo ni excesivo ni escaso el tratamiento.

12. Los medios elegidos por los emprendedores encuestados como medios con más cobertura sobre emprendimiento son Cinco Días y EFE.

13. Existe un amplio abanico de periodistas que escriben sobre este tema, no habiendo profesionales exclusivos dedicados al asunto en cuestión.

14. Para los emprendedores la visibilidad y notoriedad en medios de comunicación y redes sociales influye más en los potenciales inversores que en los clientes.

15. Los emprendedores consideran que las redes sociales otorgan más visibilidad y notoriedad que los medios de comunicación.

16. La red social que más visibilidad y notoriedad les ha dado a los emprendedores ha sido Facebook.

17. La marca es un elemento muy importante para los emprendedores que ven su mayor difusión en Internet.

18. No existe correlación entre frecuencia de aparición en medios y facilidad para crear una empresa. Que el emprendimiento aparezca más en los medios de comunicación no implica una mayor facilidad para abrir un negocio.

19. A pesar de la conclusión anterior, derivada de que los emprendedores 
encuestados constituían su empresa sobre todo con ahorros, el número de empresas creadas sí es correlacional con el incremento de cobertura sobre emprendimiento.

Los resultados pueden llevar a ciertas opiniones e implicaciones:

- El número de publicaciones sobre el emprendimiento ha aumentado significativamente, pero los datos señalan que España es uno de los países con menos facilidades a la hora de constituir una empresa. Esto implica que parte de la sociedad sea reacia a creer que se está apoyando realmente una cultura emprendedora y, sin embargo, se les responsabiliza para la salida de la actual crisis económica.

- ¿Está preparada la profesión periodística para tratar esta información de manera imparcial y con una vocación de servicio al ciudadano? Esta cuestión se hace evidente cuando mucha de la información publicada relatas historias o casos de éxito de los emprendedores o, simplemente, noticias positivas porque desde las líneas editoriales pueden hacer querer llegar al ciudadano la necesidad de ser emprendedor y acarrear llevar a esa persona al fracaso.

\section{REFERENCIAS.}

Agencia EFE http:// www.efe.com/efe/queesefe/historia/espana/1

Andréu, J. (2003). Las técnicas de Análisis de Contenido: una revisión actualizada. En: http://www.fundacion-centra.org/pdfs/S200103.PDF

Asociación para la Investigación de los Medios de Comunicación (AIMC) (2013). Estudio General de Medios (EMG). Datos recogidos desde octubre de 2012 hasta mayo de 2013. Disponible en: http://www.aimc.es/

CISE (Centro Internacional Santander Emprendimiento) y Fundación Xavier de Salas (2012) Informe GEM España 2012. Disponible en: http://www.gemconsortium.org/docs/download/2811

Cohen, L. y Manion, L (1994). Métodos de investigación educativa. Madrid. La Muralla.

Corbin, J. \& Strauss, A.(2008). The basics of qualitative research ( $3^{\mathrm{a}}$ ed.). Los Angeles, CA: Sage.

Cortés, Marc. Nanoblogging: los usos de las nuevas plataformas de comunicación en la red. España: Editorial UOC, 2009.

Del Río, R. (2004). Periodismo económico y financiero. Editorial Síntesis. Madrid.

Del Río, R. (2010). Noticias económicas, el poder de la información. En Camacho Markina, I. (2010). La especialización en el periodismo: formarse para informar. (págs. 100126) España: Comunicación Social Ediciones y Publicaciones. 
Di Palma, Gustavo (2010). Introducción al periodismo: internet y tecnología digital: prensa gráfica - radio y TV. Argentina: Editorial Brujas, 2010.

E\&E (2012). Nace "Emprendedores y Empleo". Expansión, 27/01/2012. Disponible en: $\quad$ http://www.expansion.com/2012/01/27/empleo/desarrollo-decarrera/1327681535.html

EFE (2013). Cepyme critica la ley de emprendedores por difusa y no tenerles en cuenta. $\quad$ Efeempresas 29/07/2013. Disponible en: http:// www.efeempresas.com/noticia/pymes-critica-la-ley-de-emprendedores-pordifusa-y-no-tenerles-en-cuenta/

EFEb (2013). Código Emprende se estrenará el miércoles 11 de septiembre en TVE. Efeempresas, 05/09/2013. Disponible en: http://www.efeempresas.com/noticia/codigo-emprende-septiembre-tve/

El Confidencial (2012). Las 41 startups españolas con mayor potencial de crecimiento. El Confidencial, 11/07/2012. Disponible en: http:// www.elconfidencial.com/tecnologia/2012/07/11/las-41-startups-espanolascon-mayor-potencial-de-crecimiento-2762/

Flick, U. (2007). Introducción a la investigación cualitativa. Madrid: Morata. ( $1^{\text {a }}$ Ed. de 2004).

Flores Vivar, J.M. (2009). Nuevos modelos de comunicación, perfiles y tendencias en las redes sociales. Comunicar, 33, XVII, 73-81.

Fundeu (2013). Crowfunding: major financiación colectiva, micromecenazgo... 31/05/2013 http://www.fundeu.es/recomendacion/crowdfunding-mejorfinanciacion-colectiva-financiacion-popularo-suscripcion-popular-982/

Galindo Martín, M.A. (2008). La importancia de los emprendedores ante la situación económica. Revista Parida Doble. 204 (Noviembre), 76-83.

Globalinnovationindex.org (2013). Índice Mundial de Innovación http:// www.globalinnovationindex.org/content.aspx?page=data-analysis

Gómez, M.A. (2000). Análisis de contenido cualitativo y cuantitativo: Definición, clasificación y metodología. Revista de Ciencias Humanas, 20. Disponible en: http://www.utp.edu.co/ chumanas/revistas/revistas/rev20/gomez.htm

Grijelmo, A. (1997). El estilo del periodista. Madrid. Edición Taurus. Séptima edición.

Hoycinema.com (2013). TVE prepara "sincronizados", una mirada a los emprendedores en el extranjero. ABC 19/08/2013. Disponible en: http:// www.abc.es/tv/series/20130819/abci-sincronizados-mirada- 
emprendedores-extranjero-201308161653.html

IAB Spain Research y Elogia, Marketing 4 ecommerce (2013). IV Estudio Anual de Redes Sociales. Disponible en: http://www.iabspain.net/wpcontent/uploads/downloads/2013/01/IV-estudio-anual-RRSS_reducida.pdf

Instituto Nacional de Estadística (INE). http:/ / www.ine.es

Krippendorf, K. (1997). Metodología de análisis de contenido. Teoría y práctica. Barcelona, Paidós.

Ley 11/2013 (2013). Ley 11/2013, de 26 de julio, de medidas de apoyo al emprendedor y de estímulo de crecimiento y de la creación de empleo, BOE. Disponible en: http://www.boe.es/boe/dias/2013/07/27/pdfs/BOE-A-20138187.pdf

Linera, R. (2013). Otro espacio sobre emprendedores para intentar salvar la tarde de La 1. La cadena pública estrenará 'Entre todos', un programa sobre la solidaridad, el próximo lunes. El País, 22/08/2013, Disponible en: http://cultura.elpais.com/cultura/2013/08/22/television/1377181801_918395.html

López, F. (2002). El análisis de contenido como método de investigación XXI, Revista de Educación, 4, 167-179.

Nicolás Ojeda, Miguel Ángel y Grandío Pérez, María del Mar (2012). Estrategias de comunicación en redes sociales. Usuarios, aplicaciones y contenidos. Barcelona. Editorial Gedisa.

RAE (2001). $22^{\circ}$ Edición de la RAE. Disponible en: $\underline{\text { http:/ / www.rae.es }}$

Rionda Ramírez, J.I. (2006). Microeconomía Básica. España: B - EUMED.

Rodríguez, Cl., Pozo, T. y Gutiérrez, J. (2006). La triangulación analítica como recurso para la validación de estudios de encuesta recurrentes e investigaciones de réplica en Educación Superior. RELIEVE, 12 (2). Disponible en: http://www.uv.es/RELIEVE/v12n2/RELIEVEv12n2_6.htm.

Ruiz, J. (2013). El gobierno vuelve a retrasar la aprobación de la ley de emprendedores Vozpópuli, 25/04/2013 http://www.vozpopuli.com/economia-yfinanzas / 25778-el-gobierno-vuelve-a-retrasar-la-aprobacion-de-la-ley-deemprendedores 
Servimedia (2013). El ces critica que la ley de emprendedores es confusa y compleja. El Economista, 11/06/2013. Disponible en: http://www.eleconomista.es/interstitial/volver/securitasjun13/economia/noticias $\angle 4900950 / 06 / 13 /$ El-ces-critica-que-la-ley-de-emprendedores-es-confusa-ycompleja.html

Servimedia (2013). UPTA critica que la ley de emprendedores no profundice en la financiación cuando se trata del principal problema. El Economista, 28/06/2013. http://www.eleconomista.es/economia/noticias/4951377/06/13/Upta-critica-quela-ley-de-emprendedores-no-profundice-en-la-financiacion-cuando-se-trata-delprincipal-problema.html

Spain Startup y IE Business School (2013). Mapa del Emprendimiento en España. Basados en los datos de los participantes a la Startup Competition 2013. Disponible en: http://www.spain-startup.com/media/estudio_mapa_del_empendimiento.pdf

Strauss., A. y Corbin (2002). Bases de la investigación cualitativa. Técnicas y procedimientos para desarrollar la teoría fundamentada. Bogotá: Contus Editorial Universidad de Antioquia (2 $2^{\mathrm{a}}$ Ed.). 